\title{
Growth and coarsening kinetics of gamma prime precipitates in CMSX-4 under simulated additive manufacturing conditions
}

Benjamin Wahlmann ${ }^{\mathrm{a},{ }^{*}}$, Florian Galgon ${ }^{\mathrm{a}}$, Andreas Stark ${ }^{\mathrm{b}}$, Sören Gayer ${ }^{\mathrm{b}}$, Norbert Schell ${ }^{\mathrm{b}}$, Peter Staron $^{\mathrm{b}}$, Carolin Körner ${ }^{\mathrm{a}}$

${ }^{a}$ Department of Materials Science, Chair of Materials Science and Engineering for Metals, Friedrich-Alexander-Universität Erlangen-Nürnberg, Martensstr. 5, D-91058 Erlangen, Germany; florian.galgon@fau.de, carolin.koerner@fau.de

${ }^{b}$ Institute of Materials Research, Helmholtz-Zentrum Geesthacht, Max-Planck-Str. 1, D21502 Geesthacht, Germany; andreas.stark@hzg.de, soeren.gayer@hzg.de, norbert.schell@hzg.de,peter.staron@hzg.de

* Corresponding author. Tel.: +49 9131 85-27523; fax: +49 9131 85-27515;

benjamin.wahlmann@fau.de 


\begin{abstract}
Additive manufacturing of superalloys offers new opportunities for alloy design but also poses significant processing difficulties. While the $\gamma^{\prime}$ phase is responsible for the excellent hightemperature resistance of these alloys, it also induces cracking by precipitation hardening during manufacturing. Using small-angle X-ray scattering, we characterized the dynamic precipitation, dissolution, coarsening, and morphological evolution of the $\gamma^{\prime}$ phase in situ during simulated additive manufacturing conditions. For this purpose, a CMSX-4 cylinder was subjected to cyclic heat treatment with heating and quenching rates up to $300 \mathrm{~K} / \mathrm{s}$. A specialized setup employing aluminum lenses to focus the X-ray beam was utilized to extend the q-range to small scattering vectors up to $0.035 \mathrm{~nm}^{-1}$. It was shown that the $\gamma^{\prime}$ phase precipitates extremely fast without any measurable undercooling but remains below the equilibrium fraction throughout the process. Coarsening is readily measurable over timespans of only several seconds. A fraction of the $\gamma^{\prime}$ phase that was dissolved during heating reprecipitated by forming new particles instead of growing on already existing precipitates. The findings provide new insight into the dynamic behavior of the $\gamma^{\prime}$ phase during additive manufacturing and may prove valuable in designing new superalloys and processing strategies for additive manufacturing.
\end{abstract}

Keywords: Ni-base superalloys; Phase transformations; X-ray synchrotron radiation; Nucleation and growth; Additive manufacturing

\title{
1. Introduction
}

Additive manufacturing has received increasing interest in both research and industry due to the possibility to produce parts with little geometric restrictions and fine-tuned properties. In powder bed-based additive manufacturing processes such as selective electron beam melting (SEBM), structures are built up layer by layer by selectively melting the alloy powder. The beam-scanning pattern produces a distinct temperature history for a fixed point in the manufactured part: after melting, the volume element cools down but is reheated as the beam returns to melt the adjacent section. The volume element either may be remolten or heated to a temperature below the melting point, depending on beam size, power, speed, and the scanning strategy. Multiple cooling and heating cycles follow with a continuously decreasing peak temperature during scanning of ever more distant lines, until the element cools down to the temperature of the building chamber. The chamber may be held at over $1000{ }^{\circ} \mathrm{C}$, depending on the requirements of the processed material [1]. When the next layer is melted, the pattern repeats. This alternating temperature profile leads to complex phase transformations and coarsening phenomena. Additionally, in-situ heat treatment is performed during the building process due to the high temperature of the chamber. Thermal gradients and solidification rates are very steep in SEBM. Numerical simulations yield solidification rates of the order of $100 \mathrm{~mm} / \mathrm{s}$ [2], giving rise to microstructures that are very fine and far from equilibrium. 
Nickel-base superalloys are a class of alloys that are difficult to manufacture by SEBM, but that can profit from the unique processing conditions. They contain a large volume fraction of 50$70 \%$ of ordered intermetallic $\gamma^{\prime}$ precipitates $\left(\mathrm{Ni}_{3} \mathrm{Al}, \mathrm{L}_{2}\right.$ structure) that is stable up to nearly $1300{ }^{\circ} \mathrm{C}$. These precipitates are responsible for the extraordinary high-temperature strength of these alloys, but also complicate processing by additive manufacturing. As the precipitates form at high temperatures, the ductility of the alloy decreases sharply. Thermal strains that exceed the available ductility then lead to cracking $[3,4]$. The precipitation kinetics of the $\gamma^{\prime}$ phase are very fast due to the short necessary diffusion lengths for the formation of a nucleus, which results from the similar compositions of matrix and precipitates.

As of yet, the kinetics of $\gamma^{\prime}$ precipitation have been little investigated. Most studies dealt with coarsening under isothermal aging $[5,6]$ or with precipitation in alloys with a low $\gamma^{\prime}$ volume fraction $[7,8,9]$. In these studies, a notable decrease in the $\gamma^{\prime}$ formation temperature with faster cooling rates is often observed [10]. The phase transformation rate was found to rise with faster cooling [8]. In commercial superalloys, $\gamma^{\prime}$-forming elements such as $\mathrm{Al}$ and $\mathrm{Ti}$ are present in such high amounts that the decomposition of the $\gamma$-phase cannot be suppressed even by rapid quenching [11]. The cooling rate also has a considerable impact on the morphology of the $\gamma^{\prime}$ phase. Under rapid cooling conditions of the order of $100 \mathrm{~K} / \mathrm{s}$, the precipitates are present as small, irregularly shaped particles. Slower cooling at around $1 \mathrm{~K} / \mathrm{s}$ leads to a larger, cuboidal morphology, while even lower cooling rates cause further growth and may induce splitting of the precipitates or loss of coherency [10]. Slow cooling was reported to induce the precipitation of up to three generations of $\gamma^{\prime}$ particles [9]. Successive nucleation bursts take place during continuous cooling due to the buildup of supersaturation in the $\gamma$-matrix at lower temperatures and the higher driving force for precipitation due to undercooling. Fast cooling generates a higher density of nuclei and, thus, the resulting precipitates are more evenly distributed and similar in shape, as the overlap of diffusion fields and elastic interactions limit their growth $[8,10]$. The initial formation of the first generation of $\gamma^{\prime}$ precipitates, however, has not yet been unambiguously elucidated. While most studies surmise classical nucleation, there is some evidence of spinodal decomposition at the earliest stages of $\gamma^{\prime}$ formation [12]. This mechanism has no thermodynamic barrier and may thus add to explaining the rapid phase transformation.

The thermal cycling during SEBM may induce dissolution and reprecipitation of the $\gamma^{\prime}$ phase as well as particle coarsening. As the $\gamma^{\prime}$ phase determines the high-temperature performance and processability of Ni-base alloys, a deep understanding of the mechanisms of $\gamma^{\prime}$ precipitation is necessary for further development of superalloys for additive manufacturing and process strategies. Due to the short timescales during which these phase transformations happen, they are challenging to observe experimentally. Synchrotron-radiation-based small-angle X-ray scattering (SAXS) is a method ideally suited to these investigations, offering the possibility to measure the sizes and distribution of small particles at high temporal resolution. Small-angle scattering analysis is often performed in colloid science for characterization of highly diluted particles such as polymers or proteins. In metals, this technique has been mostly used to measure particles of small volume fractions. Several authors have investigated the evolution of $\gamma^{\prime}$ size and phase fraction in Ni-base superalloys with small-angle scattering $[13,14,15,16,17]$ using neutrons and $\mathrm{X}$-rays at comparatively slow heating and cooling rates. Due to interactions between particles of different sizes and matrix inhomogeneities, such analyses remain complex. In this case, it is reasonable to work with simple models. Deschamps and De Geuser [18] 
showed that these provide sufficiently accurate information on particle size and size distribution.

In this study, we aim for a fundamental understanding of phase transformation and particle coarsening processes that take place during additive manufacturing. Therefore, we simulated the thermal history experienced by one volume element through cyclic heating and quenching of SEBM-built superalloy CMSX-4 to gain insight into the dynamic behavior of the $\gamma^{\prime}$ phase. To our knowledge, this is the first time the characterization of the $\gamma^{\prime}$ phase has been attempted at such high cooling rates.

\section{Materials and methods}

\subsection{General experimental setup}

The study was focused on the nickel-base superalloy CMSX-4 (composition: Ni-9.8 Co-6.4 Ta6.5 Cr-6.4 W-5.7 Al-2.8 Re-0.97 Ti-0.62 Mo-0.086 Hf in wt.-\%). Samples were produced by SEBM employing a process strategy developed by Ramsperger [19], which were then machined to hollow cylinders with an outer diameter of $4 \mathrm{~mm}$ and a wall thickness of $0.5 \mathrm{~mm}$. Figure 1 shows the microstructure of the $\gamma^{\prime}$ precipitates at $0.5 \mathrm{~mm}$ (a) and $1.0 \mathrm{~mm}$ (b) from the top of an SEBM-built cylinder. The $\gamma^{\prime}$ particles $0.5 \mathrm{~mm}$ below the top surface are shaped as rounded cubes with a diameter of around $70 \mathrm{~nm}$, while the particles at lower sample height are cuboidal with sharp corners and an edge length of roughly $170 \mathrm{~nm}$. Both their size distributions are monomodal. The precipitate size increases up to $500 \mathrm{~nm}$ with further distance from the sample surface. After the experiments (Fig. 1c), the microstructure consists of a bimodal distribution of rounded precipitates of $50 \mathrm{~nm}$ size and large irregular particles of $0.5-2 \mu \mathrm{m}$ size in the interdendritic region. All reported experiments were carried out consecutively with the same sample. The results of further tests with different samples are in line with the data presented here.

The SAXS measurements were performed at the high energy materials science beamline P07EH3 operated by Helmholtz-Zentrum Geesthacht at the PETRA III facility at DESY, Hamburg [20]. A dilatometer DIL 805A/D by TA instruments fitted with Kapton windows and a modified induction coil [21] to allow X-ray irradiation of the sample was used to conduct heating and quenching experiments. The sample was heated inductively with the temperature being controlled by a type S (Pt10Rh-Pt) thermocouple that was spot welded to the CMSX-4 sample. The chamber of the dilatometer was evacuated, flushed, and filled with Argon to prevent oxidation. The sample was quenched by streams of cold Argon gas blowing on the inner and outer surface, while the induction coil simultaneously regulated temperature and cooling rate. The hollow cylinder design enabled high quenching rates due to the large specific surface area.

The measurements were carried out using a photon energy of $70 \mathrm{keV}(\lambda=0.01771 \mathrm{~nm})$ to achieve sufficient transmission and intensity. The beamstop was designed in the shape of a cross with a thickness of $0.2 \mathrm{~mm}$ to extend the range of the scattering vector $q(q=4 \pi \sin \theta / \lambda$ with the full scattering angle $2 \theta$ and wavelength $\lambda$ ) to values as low as possible. This was necessary 
to observe the comparatively large $\gamma^{\prime}$ precipitates. At a sample-detector-distance of $10.5 \mathrm{~m}$, the $q$-range to be evaluated was determined as $0.035 \mathrm{~nm}^{-1}<q<1.7 \mathrm{~nm}^{-1}$, being limited by the extent of the beamstop and the decay of the signal to an isotropic background at high $q$ values. Furthermore, the beam was focused by concave aluminum lenses to increase the photon flux on the sample at small scattering angles while still being able to use the smallest available beamstop. The scattering patterns were collected on a Perkin Elmer XRD 1621 flat panel detector (resolution $2048 \times 2048$, pixel size $200 \mu \mathrm{m} \times 200 \mu \mathrm{m}$ ). Since CMSX-4 strongly absorbs X-rays, the exposure time was set to $1 \mathrm{~s}$ to acquire enough counts. The beam spot on the sample was roughly $0.23 \mathrm{~mm} \times 0.23 \mathrm{~mm}$.
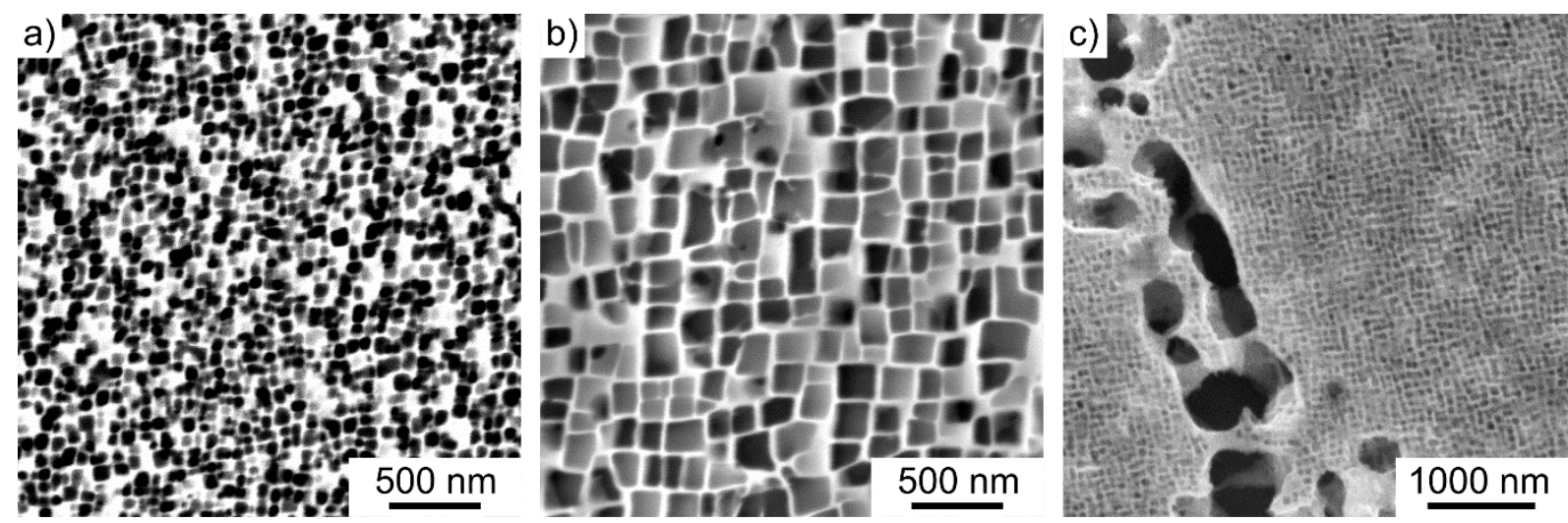

Fig. 1. SEM micrographs of SEBM-built CMSX-4: view at a) $0.5 \mathrm{~mm}$ and b) $1 \mathrm{~mm}$ below the top surface of the cylinder. c) Microstructure after heat treatment experiments.

\subsection{Experimental procedure}

Before each quenching experiment, the sample was heated to $1300{ }^{\circ} \mathrm{C}$ at a rate of $5 \mathrm{~K} / \mathrm{s}$ and held at this temperature for at least $5 \mathrm{~min}$ to dissolve the $\gamma^{\prime}$ precipitates. Ramsperger et al. [22] reported the $\gamma^{\prime}$ solvus temperature of SEBM-manufactured CMSX-4 measured by differential scanning calorimetry as $1298^{\circ} \mathrm{C}$. This is close to the solution annealing temperature we used; however, above $1300{ }^{\circ} \mathrm{C}$, the sample was at risk of melting.

To study the general phase transformation kinetics at different temperatures, the sample was quenched to 1000 and $1150{ }^{\circ} \mathrm{C}$ and aged for $25 \mathrm{~min}$. Furthermore, short quenching and holding experiments were performed. Here, the samples were only solutionized for $12 \mathrm{~s}$ and aged for $10 \mathrm{~s}$.

The thermal history of a fixed point within a built geometry during the SEBM process was simulated by repeated quenching and heating to progressively decreasing temperatures. The lower temperature represents the temperature of the building chamber, which must be at least $1000{ }^{\circ} \mathrm{C}$ for processing poorly weldable materials such as nickel-base superalloys. The chosen temperatures of 1000 and $1150{ }^{\circ} \mathrm{C}$ for single quenching or $1100{ }^{\circ} \mathrm{C}$ for multiple quenching experiments mark the borders of possible process conditions. Below $1000{ }^{\circ} \mathrm{C}$, cracks are likely to form. The maximum temperature is limited because thermal radiation from the powder bed 
can damage the electron gun. According to simulations, the cooling rates during SEBM are as high as $10^{3-} 10^{5} \mathrm{~K} / \mathrm{s}[2,23]$. Such a high value could not be achieved with the setup we employed. To extrapolate our results qualitatively to the high cooling rates in SEBM, we used two different cooling rates. The maximum mean cooling rate in the controlled mode was $200 \mathrm{~K} / \mathrm{s}$, with maximum gas flow and no regulation by the induction coil it was of the order of $300 \mathrm{~K} / \mathrm{s}$. For both, a higher peak cooling rate occurred at 0.3 to $0.5 \mathrm{~s}$ after cooling was initiated. Under controlled conditions, this rate was $500 \mathrm{~K} / \mathrm{s}$, and without control, $800 \mathrm{~K} / \mathrm{s}$.

\subsection{Data modeling and analysis}

The scattering curves (Figure 2a) were analyzed by fitting with Beaucage's global unified scattering function [24], a shape-independent model yielding several descriptors of precipitate size and distribution, and by integration. Fig. 2b) demonstrates the fits of selected curves. Detailed descriptions of the analysis procedures are given in Appendices A and B, respectively. The following parameters were obtained:

$R_{g}$ : The radius of gyration $R_{g}$ characterizes the size of irregularly shaped particles. It is defined as the average root-mean-square distance to the center of mass of the particle. Due to the strong dependence of scattered intensity on the particle size, in a polydisperse collection of particles, it is biased towards the larger precipitates.

PDI: The polydispersity index PDI provides a measure of the width of the size distribution of the $\gamma^{\prime}$ precipitates. As it increases, the distribution broadens. We assume for the $\gamma^{\prime}$ precipitates a lognormal distribution, as is often the case for metallic precipitates [25].

$\bar{R}$ : In combination with $R_{g}$, the $P D I$ allows the estimation of the number-average particle radius $\bar{R}$ as a more accurate indication of the precipitate size. It should be noted that these models either assume no specific shape or are only strictly valid for ideal spheres. Since the morphology of the $\gamma^{\prime}$ phase may change during heat treatment, we found these approximations to be appropriate to achieve a reasonable estimation of the particle size evolution.

Standard errors on the fitting parameters of Beaucage's function were obtained from the fitting software. The errors were propagated to obtain error bars on PDI and $\bar{R}$.

$Q^{\prime}$ : The integrated intensity $Q^{\prime}$ provides information about the precipitate phase fraction. The theoretical scattering contrast of the precipitates was calculated by CALPHAD (Thermo-Calc 2017b [26], database TTNI8 version 8.1) (Fig. 2c). Comparison of the computed and measured integrated intensities $Q_{0}$ and $Q^{\prime}$ (Fig. 2d) yielded a good agreement. Therefore, we determined that changes in $Q^{\prime}$ also indicate proportional variations in the $\gamma^{\prime}$ fraction. Further details on the interpretation of $Q^{\prime}$ are provided in Appendix B. 
a)
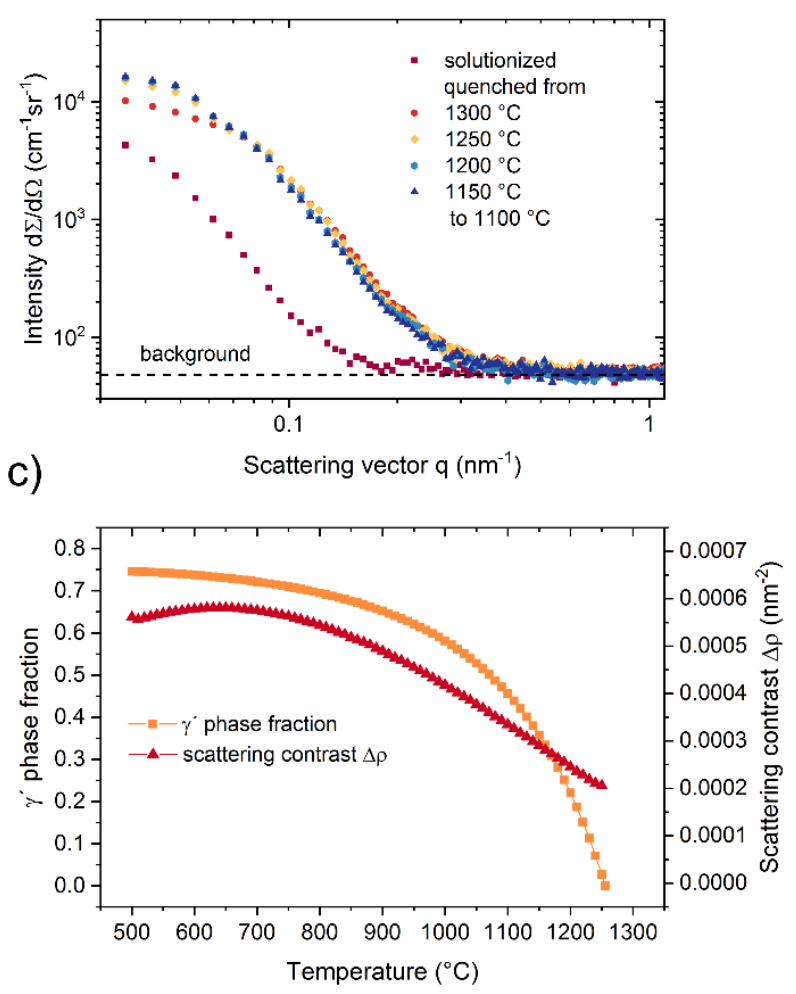

b)
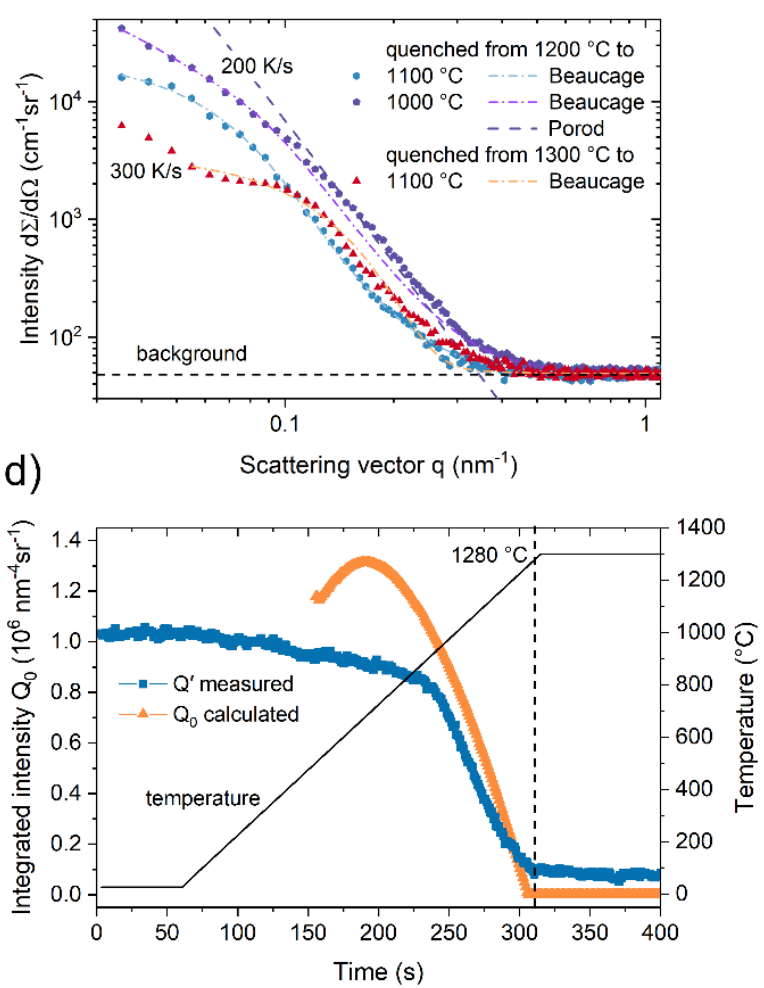

Fig. 2. Analysis of SAXS data. Panel a) shows exemplary scattering curves recorded during one thermal cycling experiment in the solutionized state and after quenching from different temperatures to $1100{ }^{\circ} \mathrm{C}$ at $200 \mathrm{~K} / \mathrm{s}$. In b), fits of the Beaucage model (eq. 1) are shown for selected curves. Panel c) depicts the evolution of $\gamma^{\prime}$ phase fraction and difference in scattering length density as a function of temperature as calculated with Thermo-Calc. In $\mathbf{d}$ ), the measured and calculated integrated intensities $Q^{\prime}$ and $Q_{0}$ are compared.

\section{Results}

\subsection{General phase transformation kinetics}

The CMSX-4 cylinder was quenched and aged isothermally at 1000 and $1150{ }^{\circ} \mathrm{C}$ for 25 min each to observe the general phase transformation and coarsening kinetics. Figure 3a) displays the evolution of $Q^{\prime}$ and of the $\gamma^{\prime}$ fraction calculated with Thermo-Calc, which represents the theoretically expected equilibrium $\gamma^{\prime}$ fraction. For better comparison, $Q^{\prime}$ at room temperature was set to the calculated $\gamma^{\prime}$ fraction at $500{ }^{\circ} \mathrm{C}$, and the $Q^{\prime}$ curve was scaled accordingly. The database becomes unreliable at lower temperatures. The $\gamma^{\prime}$ area fraction after the heat treatments determined by metallography is included as a reference.

At $1000{ }^{\circ} \mathrm{C}$ (left panel), the equilibrium $\gamma^{\prime}$ fraction is $58 \%$. $Q^{\prime}$ increases instantly to 0.47 during quenching and then grows slowly to 0.6 for $20 \mathrm{~min}$. Afterward, the rate of phase transformation decreases, though it is not entirely clear if the transformation has stopped. Therefore, the $\gamma^{\prime}$ phase could be close to or in thermodynamic equilibrium. At $1150{ }^{\circ} \mathrm{C}$ (right panel), $Q^{\prime}$ also first 
rises fast up to 0.3 when quenching, but then grows more quickly during only 1 min to a stable value of 0.35 . The constant magnitude of $Q^{\prime}$ indicates that the equilibrium state has been reached. The further development is not shown, because precipitates grew too large to be observed by our SAXS setup, which caused the apparent value of $Q^{\prime}$ to decrease.

The coarsening kinetics at different temperatures were studied by performing cyclic heating and quenching experiments with a constant peak temperature of $1300{ }^{\circ} \mathrm{C}$ and continuously decreasing aging temperatures of $1200,1150,1100,1050$, and $1000{ }^{\circ} \mathrm{C}$, as shown in Fig. $3 \mathrm{~b}$ ). Measurements at $1250{ }^{\circ} \mathrm{C}$ were also performed, but due to the low $\gamma^{\prime}$ fraction at this temperature, no reliable fits could be obtained. The coarsening rate increases rapidly with higher temperature. Coarsening is readily observable over a timescale of several seconds during aging at $1100{ }^{\circ} \mathrm{C}$ and higher. At $1100{ }^{\circ} \mathrm{C}$, the average particle radius grows at $0.14 \mathrm{~nm} / \mathrm{s}$, at $1150{ }^{\circ} \mathrm{C}$ at $0.44 \mathrm{~nm} / \mathrm{s}$, and at $1200{ }^{\circ} \mathrm{C}$ at $0.53 \mathrm{~nm} / \mathrm{s}$. It is noteworthy that the initial average precipitate size after quenching also increases with higher quenching temperature.

This phenomenon may be explained with the help of scattering curves of the aging process at 1200 and $1100{ }^{\circ} \mathrm{C}$ (Fig. 3c). The most significant differences between the curves are in the range of $0.08 \mathrm{~nm}^{-1}<q<0.4 \mathrm{~nm}^{-1}$. Since the intensity in this range is higher at $1100{ }^{\circ} \mathrm{C}$, we can conclude that more small $\gamma^{\prime}$ precipitates are present. At lower values of $q$, all curves coincide reasonably well with less significant differences. The scattering intensity at low $q$ is higher than in the solutionized state, proving the presence of large $\gamma^{\prime}$ scatterers. These observations suggest that the largest precipitates are not strongly affected by the quenching temperature, while the fraction of small precipitates formed varies greatly. Thus, the average particle size decreases with lower quenching temperature, as a higher number of small particles is formed. The radius of gyration $R_{g}$ and the polydispersity index PDI (Fig. 3d) can provide further details of the coarsening process. $R_{g}$ increases analogously to the average radius during coarsening, but the values of $R_{g}$ directly after quenching are mostly similar. Since $R_{g}$ is proportional to the mean value of the sixth power of the particle radii, it is sensitive to an increase in the fraction of large particles but less sensitive to small ones. Taking into account the average radius and the differences in precipitate fractions demonstrated by the scattering curves, the increase of $\bar{R}$ with higher quenching temperature can be attributed to the decrease of the fraction of small $\gamma^{\prime}$ precipitates. Precipitation of small particles will hardly affect the value of $R_{g}$, which is determined by the constant amount of large precipitates. $\bar{R}$, on the contrary, as the numberweighted average, is strongly shifted by small precipitates.

The PDI decreases to different extents during aging, which is indicative of a decrease in dispersity of the precipitates. As shown by the scattering curves at $1200{ }^{\circ} \mathrm{C}$ (Fig. 3c), aging causes the intensity at high $q$ to decrease, while it increases at low $q$. These changes in intensity signify that large precipitates grow, while small ones are consumed. The PDI, however, also increases with decreasing quenching temperature, which reflects the precipitation of increasing amounts of small particles as indicated by the scattering curves. 
a)
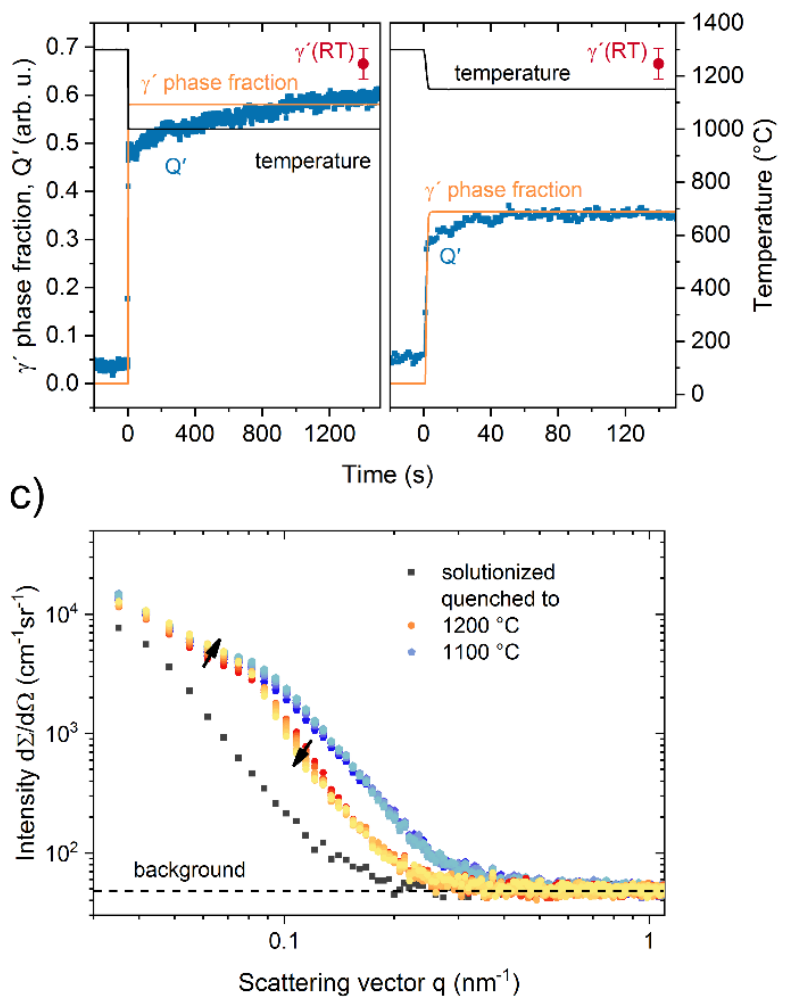

b)
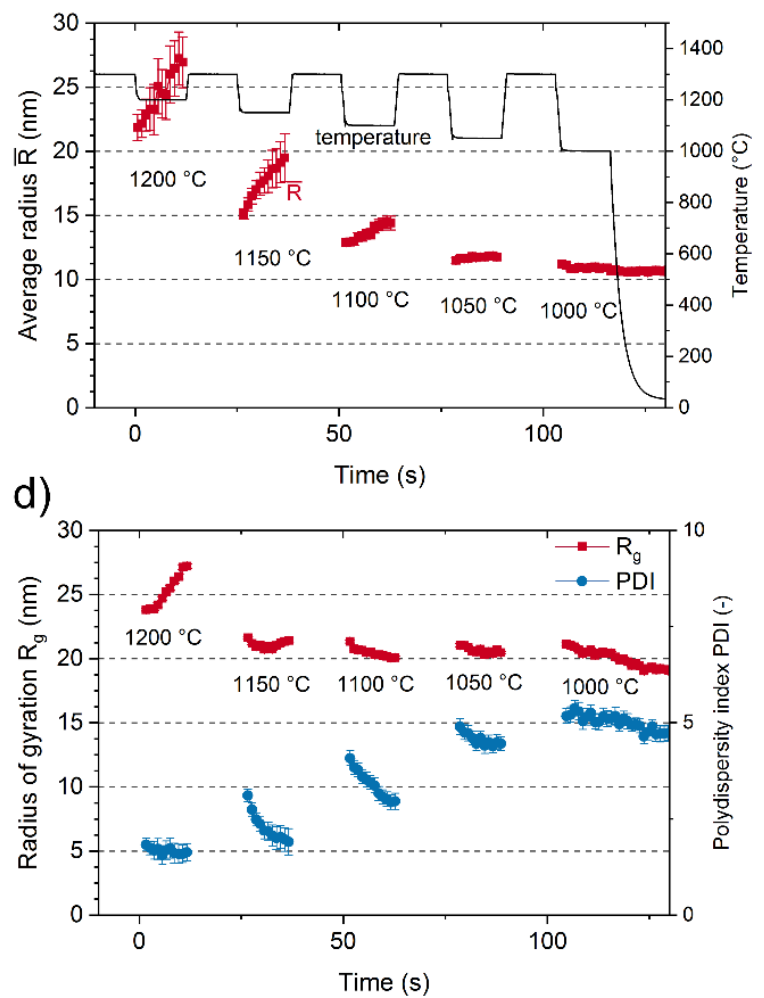

Fig. 3. General phase transformation and coarsening kinetics: a) Evolution of $Q^{\prime}$ during isothermal holding at $1000{ }^{\circ} \mathrm{C}$ (left) and $1150^{\circ} \mathrm{C}$ (right) after quenching from $1300{ }^{\circ} \mathrm{C}$. At $1000{ }^{\circ} \mathrm{C}$, the equilibrium phase fraction is reached after $20 \mathrm{~min}$, while at $1150{ }^{\circ} \mathrm{C}$ equilibrium is reached after $1 \mathrm{~min}$. Phase fractions, according to Thermo-Calc. $\gamma^{\prime}(\mathrm{RT})$ denotes the $\gamma^{\prime}$ area fraction at room temperature. b) Coarsening of precipitates at 1200, 1150, 1100, 1050, and $1000{ }^{\circ} \mathrm{C}$. c) Evolution of scattering curves during aging at 1200 and $1100{ }^{\circ} \mathrm{C}$. Arrows mark the significant changes in intensity. d) The radius of gyration and polydispersity index of precipitates during aging at different temperatures.

\subsection{Simulated additive manufacturing}

The thermal history of a volume element during the SEBM process was simulated by repeated cooling and heating to progressively decreasing temperatures. The actual temperature progression in a volume element throughout a building job is slightly more complicated than our simulated thermal profiles since the bottom temperature during cycling may not be constant, and the peak temperatures will decrease while layers are deposited successively. The actual temperature profile also depends on the process parameters and the fabricated geometry. The schematic temperature profile employed reflects the characteristics of the additive manufacturing process and is thus suitable as a general approximation. Cooling and heating rates during an SEBM process are also higher than could be achieved in these experiments. Still, the resulting phase transformation and precipitate growth processes should give valuable insight into the precipitation and dissolution dynamics. 


\subsubsection{Dynamics of $\gamma^{\prime}$ precipitation}

The evolution of the scaled $Q^{\prime}$ measure during thermal cycling is presented in Figure 4, along with the theoretical equilibrium phase fractions. Two measurement series are shown: quenching to $1000{ }^{\circ} \mathrm{C}$ in a) and to $1100{ }^{\circ} \mathrm{C}$ in b). In both cases, the nominal cooling and heating rates during cycling were $200 \mathrm{~K} / \mathrm{s}$. Quenching with $300 \mathrm{~K} / \mathrm{s}$ (Fig. 8b) showed the same general results. The $\gamma^{\prime}$ fractions calculated with Thermo-Calc serve as a guide as to what behavior would be expected under equilibrium conditions. The prior quenching and holding experiments (Fig. 3a) suggest that the alloy is not in equilibrium. The $\gamma^{\prime}$ area fraction is lower than the predicted phase fraction but shows satisfying agreement, considering the uncertainties in metallographically determined phase fractions.

Overall, the precipitation and dissolution kinetics of the $\gamma^{\prime}$ phase are very fast, with $Q^{\prime}$ reaching values of $0.35-0.4$ within 1.5 seconds. This observation coincides with phase field simulations [27]. During the short holding period at base temperature, a moderate increase of $Q^{\prime}$ is observable. Rapid heating to $1300{ }^{\circ} \mathrm{C}$ after quenching dissolves the $\gamma^{\prime}$ phase again at the same rate, as $Q^{\prime}$ drops to its former level during the solution heat treatment. For $1000{ }^{\circ} \mathrm{C}$ base temperature, quenching from supersolvus and subsolvus temperatures yields noticeably different $Q^{\prime}$ values: by quenching from $1300{ }^{\circ} \mathrm{C}$, when no precipitates are present, the maximum $Q^{\prime}$ attained is just over 0.4 . Quenching from $1250{ }^{\circ} \mathrm{C}$ and lower consistently yields $Q^{\prime}$ values over 0.5 . This difference may be explained by considering the nucleation kinetics: At supersolvus temperature, no $\gamma^{\prime}$ particles are present in the alloy, so that precipitates can only form by homogeneous nucleation. Sufficient undercooling must be achieved to overcome the free energy barrier for a nucleus to be stable. When quenching from subsolvus temperature, the $\gamma^{\prime}$ precipitates can act as nucleation sites, thus reducing the required undercooling for the precipitation of further $\gamma^{\prime}$ phase. According to classical nucleation theory, the nucleation rate decreases exponentially with an increasing free energy barrier for nucleation. The presence of $\gamma^{\prime}$ phase, therefore, facilitates nucleation and leads to faster precipitation kinetics. However, as was shown in the preceding section, the equilibrium $\gamma^{\prime}$ fraction is unlikely to be reached. It should be noted that $Q^{\prime}$ directly after quenching from $1300{ }^{\circ} \mathrm{C}$ is smaller by 0.07 for the thermal cycling experiment (Fig. 4a) than in case of quenching and holding (Fig. 3a). This discrepancy could be caused by a change in intensity of the matrix background scattering, as inhomogeneities will slowly balance out by diffusion during prolonged exposure to supersolvus temperatures.

At a base temperature of $1100{ }^{\circ} \mathrm{C}$ (Fig. 4b), $Q^{\prime}$ assumes values around 0.34 after each quench. Under this condition, a lower amount of $\gamma^{\prime}$ phase would have to form in equilibrium than at $1000{ }^{\circ} \mathrm{C}$. Judging from the development of the $\gamma^{\prime}$ fraction during aging at $1150{ }^{\circ} \mathrm{C}$ (Fig. 3b), we would not expect that the $\gamma^{\prime}$ phase reaches equilibrium during thermal cycling. Here, the holding time at $1100{ }^{\circ} \mathrm{C}$ is $12 \mathrm{~s}$, whereas equilibrium at $1150{ }^{\circ} \mathrm{C}$ was only achieved after $50 \mathrm{~s}$. At $1100{ }^{\circ} \mathrm{C}$, phase transformations will occur more slowly than at $1150^{\circ} \mathrm{C}$, and so the time until equilibrium is reached will be even higher. In contrast to $1000{ }^{\circ} \mathrm{C}$ base temperature, already present $\gamma^{\prime}$ phase does not influence the phase transformation kinetics. $Q^{\prime}$ and thus, the amount of $\gamma^{\prime}$ phase present after quenching to $1100{ }^{\circ} \mathrm{C}$ are consistently lower than after quenching from 
$1300{ }^{\circ} \mathrm{C}$ to $1000{ }^{\circ} \mathrm{C}$. The precipitate fraction is small enough so that the presence of nucleation sites does not limit the precipitation kinetics.

a)

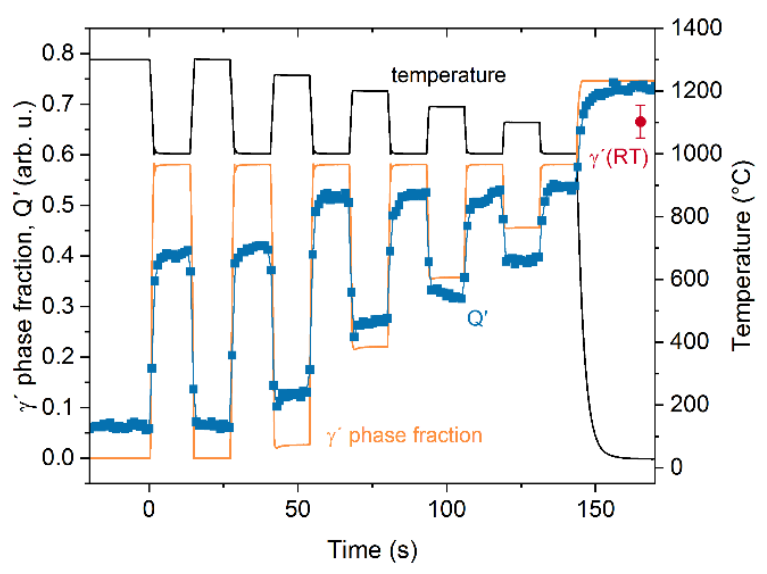

b)

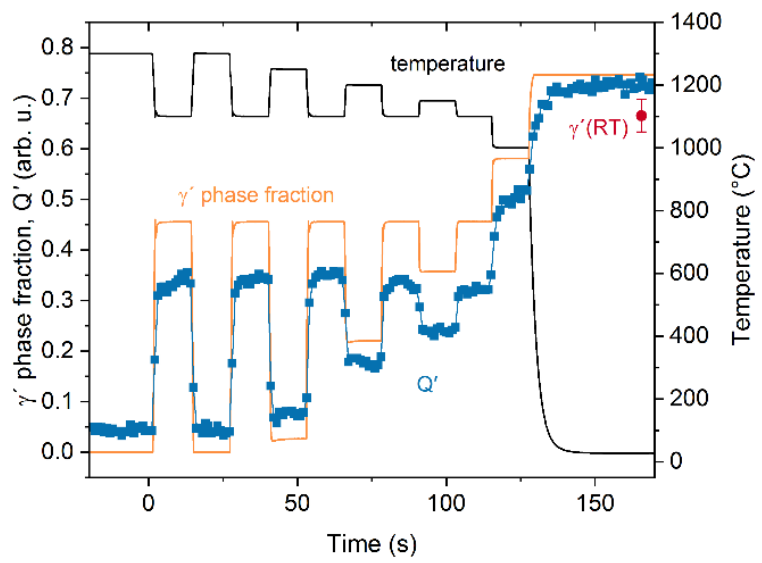

Fig. 4. Evolution of measured $Q^{\prime}$ and calculated $\gamma^{\prime}$ phase fraction during thermal cycling with quenching rate $200 \mathrm{~K} / \mathrm{s}$ and a base temperature of a) $1000{ }^{\circ} \mathrm{C}$ and b) $1100{ }^{\circ} \mathrm{C}$. In both cases, equilibrium is not reached after quenching. $\gamma^{\prime}(\mathrm{RT})$ denotes the $\gamma^{\prime}$ area fraction at room temperature.

\subsubsection{Dynamics of $\gamma^{\prime}$ precipitate coarsening}

The coarsening of the $\gamma^{\prime}$ precipitates was investigated for nominal cooling rates of 200 and $300 \mathrm{~K} / \mathrm{s}$ to evaluate their influence on the precipitate characteristics. It was observed that the evolution of the number-weighted average particle radius throughout cyclic heating and quenching depends on the base temperature and the quenching rate (Figure 5). For the sake of comparability, we restrict our discussion to coarsening processes occurring at the base temperatures of the thermal cycles or lower. During heating, the dissolution of precipitates leads to a fast increase of the mean particle size that is unrelated to coarsening, as argued in section 3.1 .

At $200 \mathrm{~K} / \mathrm{s}$ cooling rate, precipitates with an initial radius of around $10 \mathrm{~nm}$ form at both investigated base temperatures. At $1000{ }^{\circ} \mathrm{C}$, aging occurs slowly (Fig. 5a). Particles grow only notably during the high-temperature stages since diffusion processes are accelerated. No growth is visible between the first and second quenches, as all $\gamma^{\prime}$ precipitates had been dissolved by supersolvus heating. Coarsening of the $\gamma^{\prime}$ precipitates becomes readily apparent for $1100{ }^{\circ} \mathrm{C}$ base temperature. During isothermal holding at $1100{ }^{\circ} \mathrm{C}$, the average radius increases by 0.13 $0.24 \mathrm{~nm} / \mathrm{s}$ after each quench. It should be noted that the average radius directly after quenching from 1300 and $1250{ }^{\circ} \mathrm{C}$ is lower by around $1.4 \mathrm{~nm}$ than at the end of the previous holding stage at $1100{ }^{\circ} \mathrm{C}$. This decrease could have been caused by reprecipitation of $\gamma^{\prime}$ phase that was dissolved during heating.

At $300 \mathrm{~K} / \mathrm{s}$ cooling rate (Fig. 5b), due to the unregulated quenching, base temperatures are undershot for $0.5 \mathrm{~s}$ by $100-150{ }^{\circ} \mathrm{C}$. The precipitate radii after quenching from supersolvus 
temperature are around $6 \mathrm{~nm}$. We cannot differentiate between the influences of the temperature undershoot and the faster cooling rate on the precipitate size. However, since the $\gamma^{\prime}$ fraction, as indicated by $Q^{\prime}$ did not hint at any additional precipitation compared to $200 \mathrm{~K} / \mathrm{s}$ (see also Fig. $8 \mathrm{~b}$ ), we deem this effect not significant. Potential precipitation and fast dissolution of $\gamma^{\prime}$ phase cannot be ruled out but is beyond the temporal resolution of the experiments. Throughout the cycling experiment, on average, the particle sizes remained slightly below the respective values for $200 \mathrm{~K} / \mathrm{s}$. Qualitatively, the curves for both cooling rates show similar overall progressions. In contrast to the cycles at $200 \mathrm{~K} / \mathrm{s}$ and $1100{ }^{\circ} \mathrm{C}$ base temperature, at first, no coarsening is observable after quenching from $1300{ }^{\circ} \mathrm{C}$. Then, the growth rate increases sharply to $0.14-$ $0.24 \mathrm{~nm} / \mathrm{s}$. When cooling to room temperature, in all cases, a mean precipitate radius of $15 \mathrm{~nm}$ is achieved.

a)

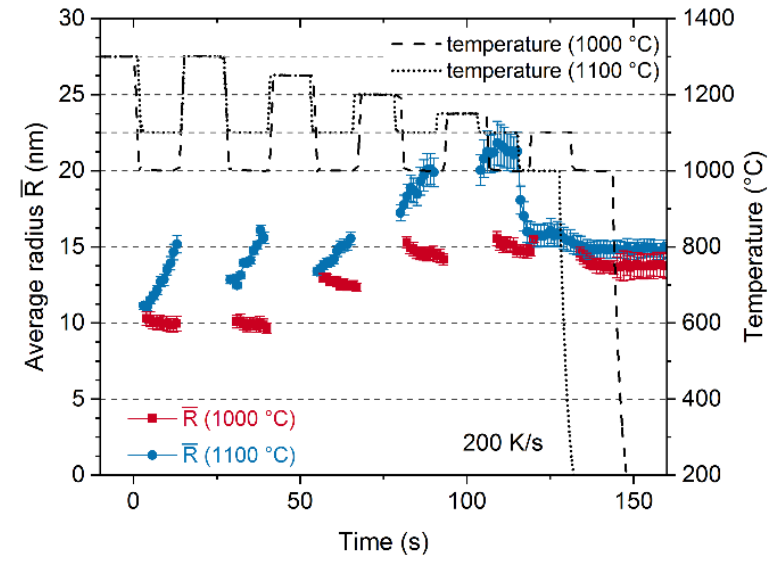

b)

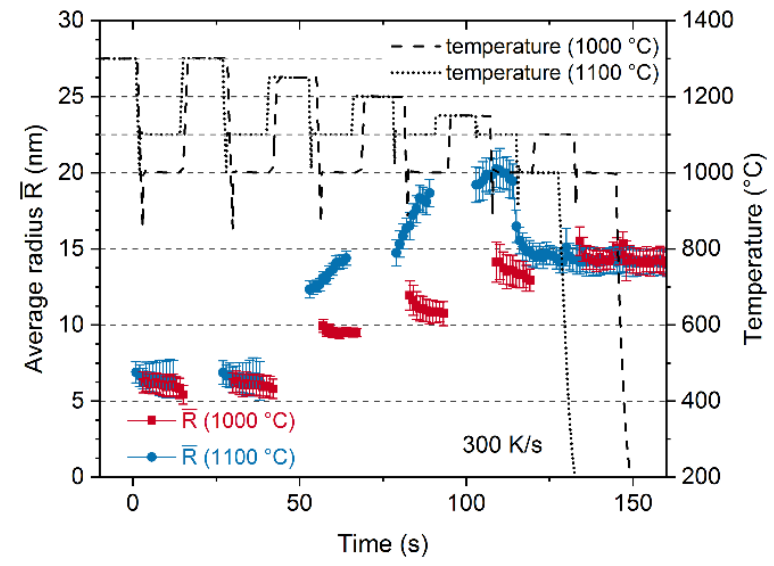

Fig. 5. Evolution of calculated mean $\gamma^{\prime}$ precipitate radius during thermal cycling for base temperatures of 1000 and $1100{ }^{\circ} \mathrm{C}$ for quenching rates of a) $200 \mathrm{~K} / \mathrm{s}$ and b) $300 \mathrm{~K} / \mathrm{s}$.

The evolutions of the radius of gyration and the polydispersity index provide further information on the coarsening processes (Figure 6). For aging at both 1000 and $1100{ }^{\circ} \mathrm{C}$ after quenching at $300 \mathrm{~K} / \mathrm{s}$, the overall increase in precipitate size is apparent by the conforming increase of $R_{g}$. After the first two quenches, a rapid increase of the PDI occurs, which could have been caused by continued precipitation of $\gamma^{\prime}$ phase. However, in this regime, the uncertainty is quite significant, and the observed surge should be considered with care. Afterward, at $1000{ }^{\circ} \mathrm{C}$ base temperature (Fig. 6a), the PDI still increases slightly during the low-temperature stages, whereas it diminishes at $1100{ }^{\circ} \mathrm{C}$. These different developments can be attributed to the different magnitudes of coarsening. While the particle growth is slow, $\gamma^{\prime}$ phase that precipitates during isothermal holding could still broaden the particle size distribution. When the coarsening rate is high, however, the effects of particle growth determine the evolution of the precipitate dispersity. Still, in both cases, the PDI decreases from quench to quench. Hence, the dispersity of the precipitate population declines throughout the thermal cycling process.

During holding at $1000{ }^{\circ} \mathrm{C}$, the mean radius and the radius of gyration decrease slowly. The reason for this behavior is not yet apparent. It is unlikely to be an artifact produced by the employed model function, as this feature also appeared when fitting other shape-independent 
models. Therefore, the decrease of both radius measurements might be caused by a shape change of the precipitates or result from our simplifying assumptions, presuming ideally spherical precipitates each having the same chemical composition and not considering effects of the high particle density. These influences might overshadow slight changes to the actual precipitate size. Notable increases of $R_{g}$ only occur between the aging stages, which supports our previous conclusion that in this case, precipitate growth only takes place during the hightemperature stages.

Regarding the first two quenches to $1100{ }^{\circ} \mathrm{C}$, it should be noted that the mean particle radius does not increase during aging (Fig. 5b), whereas $R_{g}$ rises (Fig. 6b). Therefore, particle growth must have occurred to a certain extent. In this case, it is possible that concurrent precipitation of $\gamma^{\prime}$ phase masked the coarsening.

a)
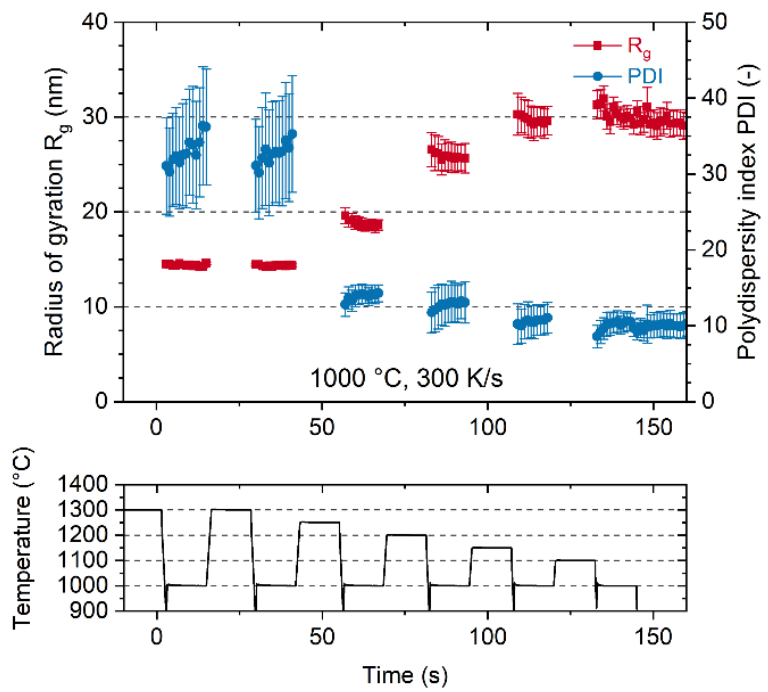

b)
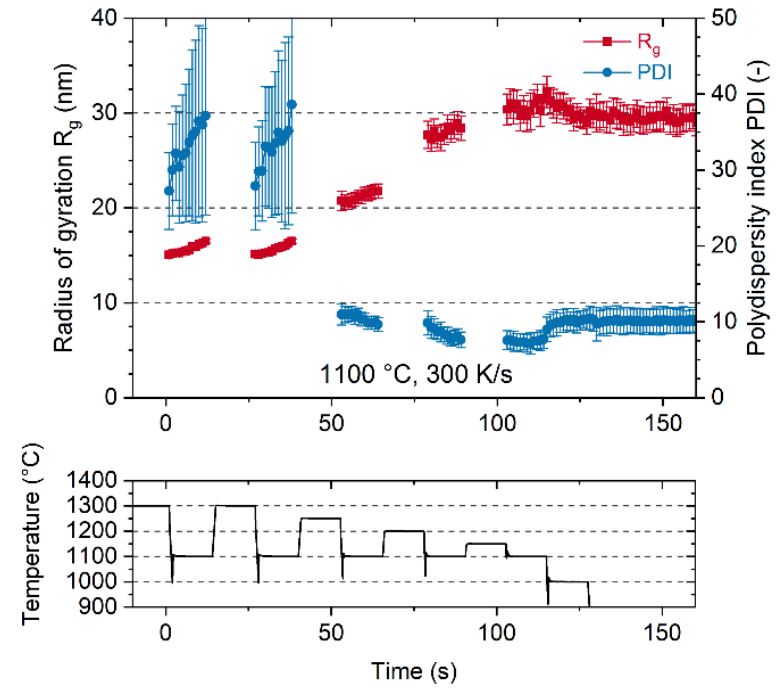

Fig. 6. Evolution of radius of gyration $R_{g}$ and polydispersity index $P D I$ during thermal cycling for a cooling rate of $300 \mathrm{~K} / \mathrm{s}$ and base temperatures of a) $1000{ }^{\circ} \mathrm{C}$, b) $1100{ }^{\circ} \mathrm{C}$.

\subsubsection{Evolution of $\gamma^{\prime}$ precipitate morphology}

The scattering pattern recorded in SAXS is the Fourier transform of the electron density distribution within the irradiated sample volume. Since the precipitates in Ni-base superalloys are distributed in a regular array, the scattering patterns are anisotropic [28]. The scattering contrast arises from the different electron densities in the precipitate and matrix phases. We can thus infer the general shape of the precipitates from the scattering patterns, as has been demonstrated by Mukherji et al. [13] and Strunz et al. [29]. As a reference to real precipitate morphologies, Figures 7a) and b) show the Fourier transforms of the microstructures in Fig. 1a) and $b$ ). The round-edged cuboids located close to the top of the cylinder create a diamondshaped scattering pattern, whereas the sharp-edged precipitates farther from the top yield a cross-shaped one. 
In Figure 7d-m) selected background-corrected scattering patterns recorded during thermal cycling with $1000{ }^{\circ} \mathrm{C}$ base temperature are presented. The measurements at $1100{ }^{\circ} \mathrm{C}$ yielded similar patterns. The shadow of the beamstop and its holder is visible as a cross in the middle of the patterns. Scattering patterns for $1300{ }^{\circ} \mathrm{C}$ and the first subsequent quench to $1000{ }^{\circ} \mathrm{C}$ are not shown, as they are identical to the patterns d) and e). At $1300{ }^{\circ} \mathrm{C}$, no precipitates should be present. The round pattern is a result of scattering from large inhomogeneities. Quenching to $1000{ }^{\circ} \mathrm{C}$ first creates a diamond-shaped pattern, which indicates that the $\gamma^{\prime}$ precipitates are likely to be shaped as rounded cubes. This morphology has also been observed in ex-situ quenching experiments [8], and laser additively manufactured samples [4]. A potential lower degree of order in the arrangement of the precipitates can also contribute to the roundedness of the pattern. Quenching from $1250{ }^{\circ} \mathrm{C}$ alters the precipitate morphology to sharp-edged cubes, as the scattering patterns adopt a cross-like shape. There is no further noteworthy change in the scattering patterns at $1000{ }^{\circ} \mathrm{C}$. However, throughout the following heating steps, the cubic precipitates develop increasingly sharp edges while the peak temperature decreases from $1250{ }^{\circ} \mathrm{C}$ to $1100{ }^{\circ} \mathrm{C}$. The cross-shaped scattering pattern is not as symmetrical as the pattern obtained from Fig. 1b), as the vertical beams of the cross are shorter than the horizontal ones. Given that the precipitates in the Fig. 1 exhibit no elongation, this was probably caused by nonideal positioning of the sample, in which the edges of the precipitates were not perfectly aligned with the synchrotron radiation beam.
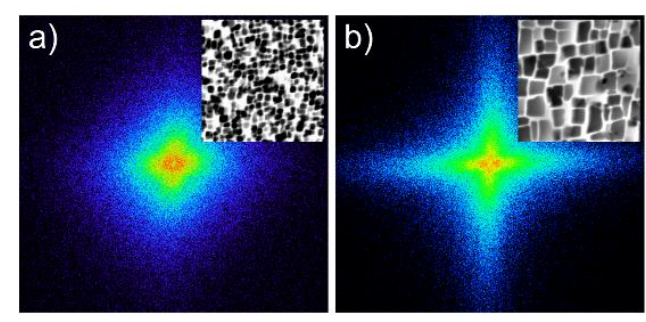

c)
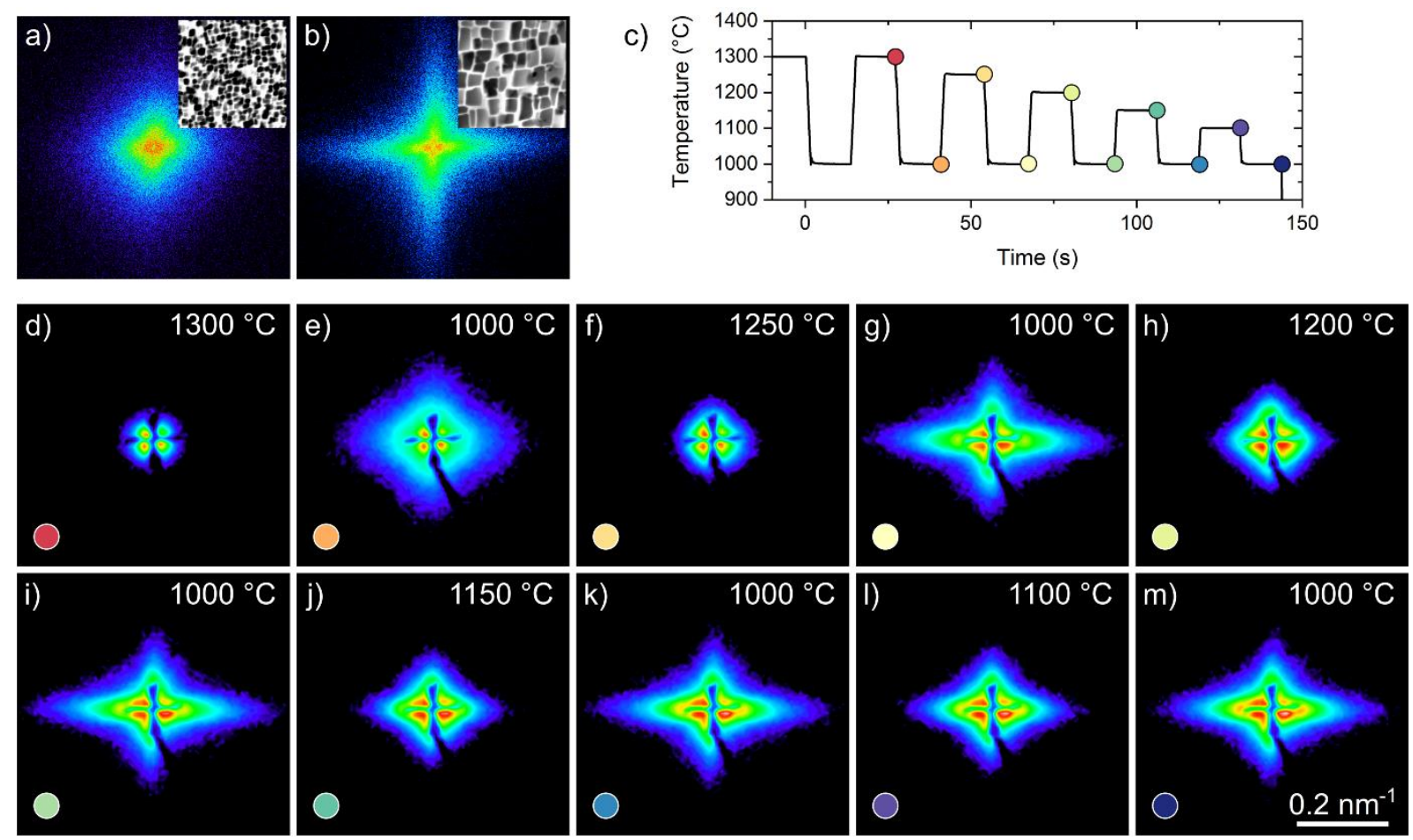

Fig. 7. Evolution of the scattering pattern during thermal cycling with $1000{ }^{\circ} \mathrm{C}$ base temperature. Panels a) and b) show Fourier transforms of the microstructures from Fig. 1. Panel c) indicates the position of the patterns in the temperature diagram with colored dots. The individual patterns (d-m) evolve from diamond-shaped to cross-shaped at the lower temperature stages, which illustrates the changes in precipitate morphology form rounded cubes 
to sharp-edged cubes. The patterns are anisotropic due to the regular arrangement of the precipitates. The cross-shaped intensity dip in the middle of each pattern is the shadow of the beamstop.

\section{Discussion}

\section{$4.1 \gamma^{\prime}$ precipitation and dissolution}

The characterization of the precipitation and dissolution of the $\gamma^{\prime}$ phase yielded details on phase transformation kinetics during cooling and heating as well as on isothermal transformations. The initial heating to the solution heat treatment temperature of $1300{ }^{\circ} \mathrm{C}$ (Fig. $2 \mathrm{~d}$ ) allows us to examine phase transformations at $5 \mathrm{~K} / \mathrm{s}$. As the curves of both computed $Q_{0}$ and measured $Q^{\prime}$ are qualitatively very similar above $900{ }^{\circ} \mathrm{C}$, we suppose that the alloy could be close to thermodynamic equilibrium at this heating rate. From room temperature to $900{ }^{\circ} \mathrm{C} Q^{\prime}$ decreased slowly at a steady rate. Utilizing X-ray diffractometry, Collins et al. [30] measured the evolution of the $\gamma^{\prime}$ phase fraction from the intensity of $\gamma^{\prime}$ superlattice reflections at $0.5 \mathrm{~K} / \mathrm{s}$ heating rate. The development of the $\gamma^{\prime}$ fraction showed a qualitatively similar curve to $Q^{\prime}$ from this study, featuring at first a slight decrease, which turns into a steep decline at elevated temperature. Collins et al. used superalloys designed for a lower operating temperature than CMSX-4. Therefore, the transitional temperature from a slow to a fast decrease of the $\gamma^{\prime}$ fraction was at $800{ }^{\circ} \mathrm{C}$ as opposed to $900^{\circ} \mathrm{C}$ in our study. Considering the findings of Collins et al., it seems plausible to assume that the $\gamma^{\prime}$ phase fraction can be estimated reasonably well as directly proportional to $Q^{\prime}$. From $1280{ }^{\circ} \mathrm{C}$ onwards, the measured $Q^{\prime}$ curve is almost constant, which indicates that the $\gamma^{\prime}$ phase has been completely dissolved. This value lies between the $\gamma^{\prime}$ solvus temperatures by Thermo-Calc $\left(1256{ }^{\circ} \mathrm{C}\right)$ and reported by Ramsperger [22] $\left(1298{ }^{\circ} \mathrm{C}\right)$. The remaining intensity is background scattering from the matrix or large inhomogeneities such as pores.

Thermal cycling (Fig. 4) allowed us insight into phase transformation kinetics at high heating and cooling rates $(200 \mathrm{~K} / \mathrm{s})$. Here, we interpret the $\gamma^{\prime}$ fraction as directly proportional to $Q^{\prime}$. We do not consider the influence of the precipitate size on composition because the measured average radius of the precipitates was always greater than $5 \mathrm{~nm}$ and thus deemed to have a negligible effect. This assumption is supported by investigations by Chen et al. [31], who demonstrated that for $\gamma^{\prime}$ precipitates of $5 \mathrm{~nm}$ radius, the interfacial tension could only account for $5 \%$ of compositional variations from equilibrium. The transformation rates for precipitation and dissolution are about half as high as predicted for equilibrium conditions when quenching from high temperature $\left(1300\right.$ and $\left.1250^{\circ} \mathrm{C}\right)$, as shown in Figure 8a). When the temperature differences are smaller than $150{ }^{\circ} \mathrm{C}$, however, transformation rates are just slightly lower than or equal to equilibrium conditions.

Precipitation kinetics of the $\gamma^{\prime}$ phase are known to be extremely rapid, as precipitation cannot be entirely suppressed by quenching after solution heat treatment. Such fast kinetics suggest that during the formation of $\gamma^{\prime}$ precipitates from the matrix only little rearrangement of atoms 
is required. Since the ordered $\mathrm{L1}_{2}$ lattice has the same face-centered cubic crystal structure as the matrix, it can be assumed that only a few atoms must switch places to form a precipitate nucleus. The high coherency of the precipitates with the matrix also leads to a low nucleation barrier. Apart from Ni, Al is the principal constituting element of the $\gamma^{\prime}$ phase. Al is a fast diffuser in superalloys [32], which facilitates the rapid nucleation of $\gamma^{\prime}$ phase. The dissolution of the $\gamma^{\prime}$ phase upon heating is equally fast as precipitation because diffusion and thus the phase transformation process is accelerated exponentially with increasing temperature.

Precipitation processes can be described semi-analytically by the Johnson-Mehl-Avrami (JMA) equation [33]. This model predicts an S-shaped transformation profile where the transformation rate first increases fast upon cooling and drops slowly after the maximum transformation rate has been reached. Masoumi et al. [8] demonstrated that the precipitation of $\gamma^{\prime}$ phase in a turbine disk alloy with $40 \% \gamma^{\prime}$ volume fraction could be described accurately using a modified JMA model. The phase transformation profiles for fast cooling and heating of the high $\gamma^{\prime}$ containing alloy CMSX-4, however, show substantially different curves. As shown in Fig. 8a), the transformation rate takes the form of a steep spike. No asymmetric profile of the transformation rate as is characteristic for the JMA model can be distinguished. This observation can be attributed to two effects: First, due to the higher transformation temperature, the formation of nuclei by diffusional processes is much faster than measured in Masoumi's work. Second, the higher concentration of $\gamma^{\prime}$-forming elements compared to disk alloys allows short diffusion lengths and thus accelerates nucleation. In contrast to low $\gamma^{\prime}$-containing alloys, there is no evidence of supercooling within the temporal resolution of our measurements.

Even though the transformation from $\gamma$ to $\gamma^{\prime}$ is fast, the precipitated amount of $\gamma^{\prime}$ phase is lower than the equilibrium fraction for all temperatures investigated (Figs. 4, 8b). As quenching proceeds, the decreasing temperature promotes the phase transformation due to the increased driving force at a lower temperature. When quenching stops, the rate of phase transformation slows down instantly. Since the $\gamma^{\prime}$ phase is not in a state of thermodynamic equilibrium, there exists a driving force for further phase transformation. As more $\gamma^{\prime}$ phase precipitates, however, the driving force diminishes, leading to a continuous decline of the rate of transformation. This behavior is visible clearly for aging times of 2.5 and $25 \mathrm{~min}$ (Fig. 3a), and slightly during the short aging period at base temperature during thermal cycling (Fig. 4). In the latter case, the repeated heating and dissolving of the $\gamma^{\prime}$ phase delay the transformation at base temperature. Except for the quench from 1250 to $1000{ }^{\circ} \mathrm{C}$, there is no significant further increase of the $\gamma^{\prime}$ fraction at base temperatures of 1000 and $1100^{\circ} \mathrm{C}$. Given the overall short aging time of about $50 \mathrm{~s}$ at base temperature, it is unlikely that the equilibrium phase fraction is approached after any of the thermal cycling processes.

\section{$4.2 \gamma^{\prime}$ precipitate coarsening during thermal cycling}

The initial precipitate sizes after quenching with a higher cooling rate $(300 \mathrm{~K} / \mathrm{s})$ are smaller than for a lower rate $(200 \mathrm{~K} / \mathrm{s})$. This behavior is expected since a higher quenching rate allows less time for diffusional growth of the precipitates.

Combining the evolution of precipitate phase fraction, average precipitate size, as well as the radius of gyration and the polydispersity index as indicators of the size distribution, provides 
further insight into the precipitation and growth processes during thermal cycling, as shown in Fig. 8b) at the example of $1100{ }^{\circ} \mathrm{C}$ and $300 \mathrm{~K} / \mathrm{s}$. Coarsening of the $\gamma^{\prime}$ particles is readily apparent over the short timespans of aging at base temperature by the increase of the average particle radius and the radius of gyration. While the sample is held isothermally, only little additional $\gamma^{\prime}$ phase precipitates. Therefore, the precipitate growth must be caused for the most part by ripening. Because the dispersity decreases while the mean particle size grows, as indicated by the decline of the $P D I$, precipitate growth must proceed by consumption of the small particle fraction, since these have a higher solubility in the matrix than the larger ones. This process is characteristic for diffusion-limited Ostwald ripening, which is often observed in superalloys.

The evolutions of average precipitate radius and radius of gyration together provide further clues about the reprecipitation of $\gamma^{\prime}$ phase that was dissolved previously during heating. Here, we consider the fourth quench at $1100{ }^{\circ} \mathrm{C}$ and $300 \mathrm{~K} / \mathrm{s}$ (Figs. 5a, 6b, 8b). Extrapolating the precipitate growth that takes place during the third aging stage leads to a mean radius of roughly $17 \mathrm{~nm}$, which is larger by $2 \mathrm{~nm}$ than the calculated radius after the fourth quench. The particle size seems to have hardly increased during the intermediate high-temperature stage. The radius of gyration, by contrast, exhibits a notable increase from 22 to $28 \mathrm{~nm}$. Since $R_{g}$ is sensitive to the growth of the larger particles, its increase reflects the coarsening taking place during the high-temperature period. The delay in increase of the mean particle radius could only have been caused by the formation of precipitates that are smaller than the current mean size. These would result from the precipitation of $\gamma^{\prime}$ phase during quenching. In section 3.2.1, it was argued that existing particles facilitate reprecipitation of the $\gamma^{\prime}$ phase by acting as nucleation sites. Therefore, only a fraction of the $\gamma^{\prime}$ phase could have contributed to the formation of these smaller precipitates.

Indications of the same reprecipitation phenomenon are also observable for the following quench as well as for the third to fifth quenches at $200 \mathrm{~K} / \mathrm{s}$ and $1100{ }^{\circ} \mathrm{C}$. The effect becomes less notable at higher base temperature and with decreasing peak temperature of the intermediate heating periods because less $\gamma^{\prime}$ phase is dissolved due to the lower temperature differences. To clarify the precipitation kinetics further, however, numerical modeling of the precipitation processes would be required, which is beyond the scope of this paper.

The quenching rate has no discernible influence on the coarsening kinetics of the $\gamma^{\prime}$ phase. However, the initial size of the precipitates after the first quench as well as the average precipitate sizes during aging become smaller at the higher quenching rate. In a real additive manufacturing process, far higher cooling rates of the order of $10^{3}-10^{5} \mathrm{~K} / \mathrm{s}$ would be expected. Consequently, the mean precipitate size would be still smaller. According to the measurements presented here, the coarsening kinetics are significantly determined by the base temperature. Therefore, the temperature of the building chamber would exert a far stronger influence on the coarsening behavior of the $\gamma^{\prime}$ precipitates than the actual cooling rate. The duration of the experiments was not long enough to reliably determine any effects of precipitate coarsening during thermal cycling on the subsequent coarsening during the in-situ heat treatment while the part is aged at the process temperature for several hours. Cooling to room temperature after the short thermal cycles, though, led to almost identical precipitate sizes in all cases. Since the several-hour-long in-situ aging in SEBM will entail far stronger changes to the precipitate size than the thermal cycles, the final precipitate size will be defined by the process temperature. A 
high process temperature mediates effects such as cracking. As such, these effects should not depend on precipitation processes occurring during the final cooling after the build is finished but could be influenced by the precipitation dynamics induced by the thermal cycles.

\subsection{Effects on $\gamma^{\prime}$ precipitate shape}

The shape of the $\gamma^{\prime}$ precipitates is determined by their interfacial energy and the elastic energy caused by the lattice misfit between precipitate and matrix phase. As the elastic energy is proportional to the particle volume, while the interfacial energy is proportional to its surface area, the elastic energy contribution will dominate at large precipitate sizes. To reduce the elastic energy, the precipitate will adopt a cuboidal shape and align the cube faces along the elastically soft $\langle 001\rangle$ directions, creating an ordered array of $\gamma^{\prime}$ cubes [34]. The lattice misfit in CMSX-4 is negative, i.e., the lattice constant of the $\gamma^{\prime}$ phase is smaller than that of the matrix. It is constant from room temperature up to $800{ }^{\circ} \mathrm{C}$ and then decreases to more negative values at higher temperature [27,35]. Furthermore, it was shown that the fraction of larger particles increases with higher temperature. Therefore, one might expect a more pronounced cubic shape at higher temperatures.

In contrast, the reverse behavior is observable. From 1250 to $1100{ }^{\circ} \mathrm{C}$, the precipitate shape seems to become more rounded with higher temperature. However, since the $\gamma^{\prime}$ phase fraction is lower at a higher temperature, the average distance between particles will increase, leading to diminishing elastic interactions and a less ordered array. The loss of order would result in a more isotropic scattering pattern. This hypothesis is supported by studies on the dissolution mechanisms of $\gamma^{\prime}$ precipitates [10]. The authors argued that elastically constrained precipitates do not dissolve uniformly, but rather individually, depending on the local stability of the $\gamma^{\prime}$ array.

As shown in Figs. 7e-g), the particle shape changes from rounded to angular cubes between the quenches from 1300 and $1250{ }^{\circ} \mathrm{C}$ to the building temperature of $1000{ }^{\circ} \mathrm{C}$. This transformation could be caused by a change in the composition of the matrix and precipitate phases. The $\gamma^{\prime}$ phase fraction after quenching from supersolvus temperature is probably farther from equilibrium than after quenching from subsolvus temperature, since some diffusional equilibration should have been able to take place at $1250{ }^{\circ} \mathrm{C}$. This process may have led to a difference in the respective compositions of the phases and thus to a change in lattice misfit. A lower lattice misfit would have promoted a more rounded precipitate shape. It is also possible that, due to the smaller size, the interfacial energy exerted a stronger influence on the precipitate shape than the elastic energy contribution. Finally, a less regular arrangement of the precipitates may also have reduced the sharpness of the scattering pattern. Transitions of shape and arrangement of the precipitates by diffusion-limited processes are expected to be expedited during the high-temperature stage of $1250{ }^{\circ} \mathrm{C}$, which may explain the disparities between Fig. $7 \mathrm{e}$ ) and $\mathrm{g}$ ). Due to the non-equilibrium conditions and the complex effects on $\gamma^{\prime}$ morphology, a more precise assessment of these effects cannot be achieved. 
a)

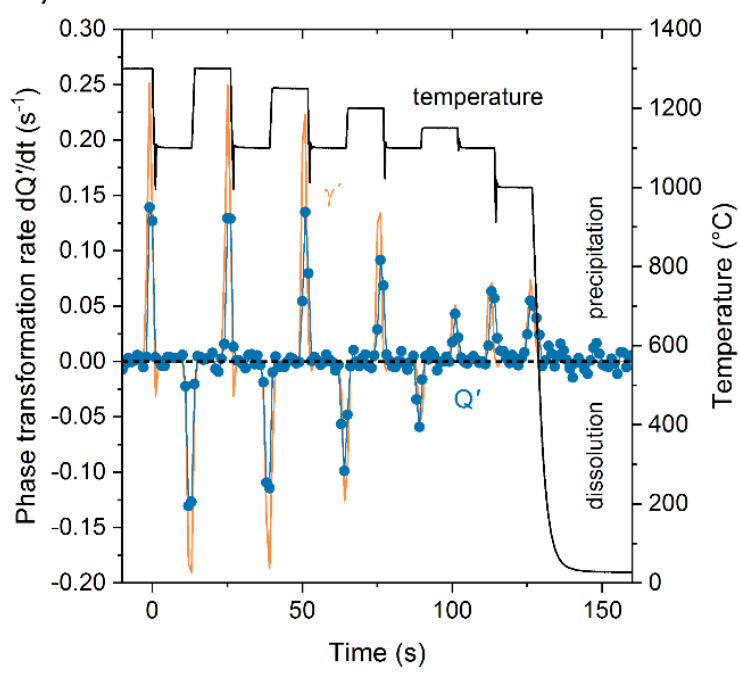

b)

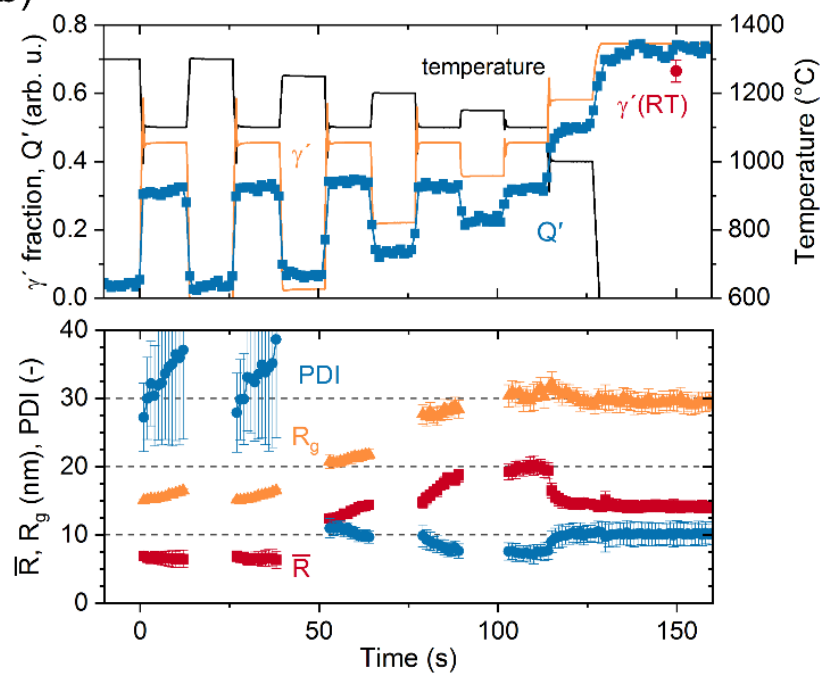

Fig. 8. Complementary key results of thermal cycling experiments exemplified by measurements at $1100{ }^{\circ} \mathrm{C} / 300 \mathrm{~K} / \mathrm{s}$ : a) The phase transformation rate allows a better understanding of the kinetics of the phase transformations. b) The evolution of $\mathrm{Q}^{\prime}$ provides information about the precipitation of the $\gamma^{\prime}$ phase while coarsening of the $\gamma^{\prime}$ precipitates can be tracked using the mean precipitate radius, the radius of gyration and the polydispersity index.

\section{Conclusions}

The characterization of the $\gamma^{\prime}$ phase in the Ni-base superalloy CMSX-4 using SAXS yielded insight into the dynamics and kinetics of precipitation, including dissolution, coarsening, and shape change, during additive manufacturing. SAXS is well suited for this type of investigation due to the possibility to gain statistically significant information about precipitate sizes and phase fractions at a high temporal resolution. The scattering patterns provided information about the changes in the morphology of the precipitates throughout the process by relating these to the existing microstructures in an as-built CMSX-4 sample. Although the $\gamma^{\prime}$ precipitates are densely packed, valuable information could be extracted by applying shape-independent model functions. Based on the complementary evaluation of the particle size and phase fraction, the following conclusions can be drawn:

- Precipitation of the $\gamma^{\prime}$ phase is fast, but still only about half as fast as predicted for equilibrium conditions. The equilibrium $\gamma^{\prime}$ phase fraction is not reached for up to $20 \mathrm{~min}$ when aging at $1000{ }^{\circ} \mathrm{C}$. Therefore, the $\gamma^{\prime}$ phase was never in equilibrium in the heating/quenching experiments. The presence of $\gamma^{\prime}$ nuclei facilitated precipitation.

- The shape of the precipitates is dominated by their size, which determines the magnitude of misfit effects. Quenching from supersolvus temperature created round precipitates, while quenching from subsolvus temperatures consistently yielded sharp-edged particles. The scattering patterns indicate a transition from rounded to angular particles or an increase in particle order as the temperature decreases. 
- Reprecipitation of dissolved $\gamma^{\prime}$ phase occurs by the growth of existing particles and nucleation of new precipitates. The formation of precipitates with a size smaller than the average particle radius compensates the coarsening taking place during exposure to high temperatures to a certain extent.

- A real additive manufacturing process typically features faster cooling and heating rates. Therefore, initial precipitate sizes will be smaller than observed in this study. The process temperature will mainly determine the long-term coarsening kinetics. The findings discussed in this paper provide a deeper understanding of the dynamic processes occurring during $\gamma^{\prime}$ precipitation and dissolution. These will be beneficial in optimizing high $\gamma^{\prime}$-containing superalloys and process strategies for additive manufacturing.

\section{Acknowledgments}

We acknowledge DESY (Hamburg, Germany), a member of the Helmholtz Association HGF, for the provision of experimental facilities. Parts of this research were carried out at PETRA III, and we would like to thank Jan Rosigkeit for his great support in operating the beamline P07. We thank Julian Pistor for providing the SEBM-built CMSX-4 samples. We also thankfully acknowledge financial support by the German Research Foundation (DFG) and the Cluster of Excellence Engineering of Advanced Materials.

\section{Appendix A. Determination of particle size measures}

The SAXS data were corrected for instrument background and shadowing by the beamstop and then averaged azimuthally with the program DPDAK [36]. The scattering curves were then scaled to absolute intensity $d \Sigma / d \Omega$ by calibration with a glassy carbon standard provided by Jan Ilavsky [37]. Selected curves from the solutionized state and after quenching at $200 \mathrm{~K} / \mathrm{s}$ to $1100{ }^{\circ} \mathrm{C}$ are shown in Figure 2a). To account for the remaining isotropic background noise $I_{B G}$ from incoherent scattering of the solid solution matrix [38], we plotted $I q^{4}$ vs. $q^{4}$ over the entire integrated $q$-range $\left(0.035 \mathrm{~nm}^{-1}<q<1.7 \mathrm{~nm}^{-1}\right)$. $I_{B G}$ could then readily be determined as the linear slope of this curve [39]. The background was subtracted for all subsequent data processing steps. In the solutionized state scattering is still observed. This intensity is probably contributed by the matrix and large inhomogeneities or small pores.

During cooling, the $\gamma^{\prime}$ precipitates change shape in dependence of the lattice misfit between the precipitate and matrix phase and the precipitate size. Therefore, it is difficult to determine an appropriate form factor for the precipitates. Furthermore, since the $\gamma^{\prime}$ phase fraction is high above $50 \%$ at $1000{ }^{\circ} \mathrm{C}$ in equilibrium state - the precipitate particles cannot be treated as diluted, which is required for the application of most model functions. To describe the particle shape, size, and distribution accurately, a structure factor describing the interaction between the 
particles would be required. Thus, we used shape-independent functions as a more robust method to model the scattering curves.

Beaucage's global unified scattering function [24] was fitted to the scattering curves to obtain information about the precipitate size and distribution:

$$
I(q)=G \exp \left(\frac{-q^{2} R_{g}^{2}}{3}\right)+K_{p}\left(\frac{q}{\left[\operatorname{erf}\left(q R_{g} / 6^{1 / 2}\right)\right]^{3}}\right)^{-4}
$$

where $G$ is a scaling factor, $R_{g}$ the radius of gyration, and $K_{p}$ the Porod constant. Selected fits of the model to scattering curves are shown in Fig. 2b). The scattering curves obtained from the cycling experiments with $300 \mathrm{~K} / \mathrm{s}$ cooling rate as well as the short aging trials exhibited a kneelike shape that could not be reproduced well by the Beaucage model. This feature was considered to be caused by large background scatterers. Therefore, these curves were only fitted in the range $0.055 \mathrm{~nm}^{-1}<q<1.7 \mathrm{~nm}^{-1}$ to exclude the knee from the fit. Additionally, a satisfying fit in the medium q-range could not be achieved in these cases because the Porod region of the curve was not represented adequately. Corresponding curves are shown for quenching from $1300{ }^{\circ} \mathrm{C}$ to $1100{ }^{\circ} \mathrm{C}$ in Fig. 2b). Instead, the Porod constant $K_{p}{ }^{\prime}$ was determined from the following fit over the range $0.13 \mathrm{~nm}^{-1}<q<0.27 \mathrm{~nm}^{-1}$ :

$$
I(q)=\frac{K_{p}{ }^{\prime}}{q^{4}}
$$

According to Beaucage et al. [40], we can estimate the width of the particle size distribution of the scattering particles from the parameters of the fit function by calculating the polydispersity index PDI:

$$
P D I=\frac{K_{p}{ }^{\prime} R_{g}^{4}}{1.62 G}
$$

The PDI describes the dispersity of a size distribution function in relation to monodisperse spheres. Technically, this PDI is only valid for spherical particles. The $\gamma^{\prime}$ precipitates, however, are mostly cuboidal, which may lead to quantitative inaccuracies. Our results, though, will still illustrate qualitative trends. To acquire a measure of the medium particle size, we need to assume a size distribution. We chose a lognormal size distribution of the radius $r$ of the precipitates:

$$
f(r)=\frac{1}{r \sigma \sqrt{2 \pi}} \exp \left(-\frac{(\ln (r / m))^{2}}{2 \sigma^{2}}\right) .
$$


This distribution is often a valid approximation for size distributions resulting from nucleation and growth processes such as in the case of metallic precipitates [25]. The standard deviation $\sigma$ and median particle radius $m$ of the distribution function are given by

$$
\begin{gathered}
\sigma=\left(\frac{\ln (P D I)}{12}\right)^{1 / 2} \\
m=\left(\frac{5 R_{g}^{2}}{3 \exp \left(14 \sigma^{2}\right)}\right)^{1 / 2} .
\end{gathered}
$$

Finally, from $\sigma$ and $m$, we calculate the number-weighted radius $\bar{R}$ of the particles:

$$
\bar{R}=\exp \left(\ln (m)+\frac{\sigma^{2}}{2}\right) .
$$

It should be noted that $m$ and $\bar{R}$ are smaller than $R_{g}$. In polydisperse systems, $R_{g}$ is strongly biased to the larger particles, since the scattered intensity is weighted with the sixth power of the particle radius.

\section{Appendix B. Estimation of the $\gamma^{\prime}$ phase fraction}

The integrated intensity $Q_{0}$ is related to the volume fraction $\phi$ and contrast $\Delta \rho$ of scatterers: $Q_{0}=2 \pi^{2}\left(\Delta \rho^{2}\right) \phi(1-\phi)$. Thus, with knowledge of the scattering contrast, information about the precipitate phase fraction can be obtained. $Q_{0}$ is defined as the integral from zero to infinity over the product of intensity and the squared scattering vector. Since our q-range is finite, we approximate the integrated intensity as $Q^{\prime}$. Taking into account the background intensity $I_{B G}$, it is calculated as follows:

$$
Q^{\prime}=\int_{q_{\min }}^{q_{\max }} q^{2}\left(I(q)-I_{B G}\right) d q
$$

We determined the integration range as $0.035 \mathrm{~nm}^{-1}<q<0.6 \mathrm{~nm}^{-1}$. The upper limit was defined at the value where the scattered intensity from the $\gamma^{\prime}$ precipitates deteriorated to zero. The scattering contrast $\Delta \rho$ has to be determined from the chemical compositions of matrix and precipitates; thus, it can have a substantial uncertainty [14]. As $Q_{0}$ is consistently 
underestimated by $Q^{\prime}$, we cannot infer precipitate volume fractions directly, but we can still make qualitative statements about the evolution of phase fractions.

The thermodynamics of nickel-base superalloys can be predicted reasonably well with CALPHAD methods [41]. Using the software Thermo-Calc 2017b [26] along with the database TTNI8 (version 8.1), we calculated phase fractions and compositions, which allowed us to estimate the evolution of the scattering contrast. The calculated $\gamma^{\prime}$ fraction and scattering contrast as a function of temperature are displayed in Fig. 2c). The equilibrium composition of the $\gamma^{\prime}$ phase remains almost constant over the evaluated temperature range. Consequently, the contrast change is mainly caused by the changing concentration of elements in the matrix, which depends on the amount of present $\gamma^{\prime}$ phase. At low temperatures, the thermodynamic database becomes unreliable. Therefore, we did not include any computations below $500{ }^{\circ} \mathrm{C}$. The predicted $\gamma^{\prime}$ solvus temperature is $1256^{\circ} \mathrm{C}$; at a higher temperature, both calculated contrast and precipitate phase fraction drop to zero.

From these values, the theoretical $Q_{0}$ curve was computed and compared to the measured integrated intensity $Q^{\prime}$ during heating of an as-built sample from room temperature to $1300{ }^{\circ} \mathrm{C}$ (Fig. 2d). Both curves show a good match in the range from 250-300 s (950-1200 ${ }^{\circ} \mathrm{C}$ ), which suggests that $\gamma^{\prime}$ phase fraction and scattering contrast could be close to the theoretically predicted equilibrium conditions. The calculated curve exhibits a distinct maximum at $190 \mathrm{~s} / 670^{\circ} \mathrm{C}$, whereas the measured curve is strictly increasing towards lower temperatures. This discrepancy could be due to slower diffusion at lower temperatures, whereby the equilibrium composition cannot be reached. Since the exact scattering contrast is still difficult to determine and changes significantly with temperature, reliable $\gamma^{\prime}$ fractions cannot be calculated. Further errors are introduced by thermodynamic calculations, which do not precisely reflect the real state of the material, and the anisotropy of the scattering pattern. Instead, $Q^{\prime}$ will be used for qualitative comparisons, since both $Q^{\prime}$ and the $\gamma^{\prime}$ fraction exhibit a monotonic behavior over the examined temperature range $\left(1000-1300^{\circ} \mathrm{C}\right)$. Thus, an increase in $Q^{\prime}$ also signifies an increase in the $\gamma^{\prime}$ phase fraction.

When interpreting the development of $Q^{\prime}$ regarding the evolution of the $\gamma^{\prime}$ phase fraction, the effects of particle size on the chemical composition of the precipitates should be considered. The equilibrium composition of small precipitates is different from that of larger ones due to their higher surface curvature, which causes a higher solubility in the matrix. The contribution of small particles to $Q^{\prime}$ might, therefore, be not proportional to their volume. The solubility limit $X_{e q}$ of precipitates is often approximated as

$$
X_{e q}=X_{e q, \infty} \exp \left(\frac{2 \gamma V_{m}}{r R T}\right)
$$

where $X_{e q, \infty}$ is the solubility limit in an infinitely large precipitate, $\gamma$ the surface energy, $V_{m}$ the molar volume, $r$ the radius of the precipitate, $R$ the molar gas constant, and $T$ is the temperature [42]. The surface energy can be estimated at roughly $0.035 \mathrm{~J} / \mathrm{m}^{2}$ with Thermo-Calc. The molar volume of the precipitates can be approximated with that of nickel. Considering a value of $6.59 \times 10^{-6} \mathrm{~m}^{3} / \mathrm{mol}$, we obtain at $1000^{\circ} \mathrm{C}$ a correction factor $X_{e q} / X_{e q, \infty}$ for the solubility limit of 
1.05 for a radius of $1 \mathrm{~nm}$ and a factor of 1.01 for $5 \mathrm{~nm}$. At higher temperature, this factor is reduced further. These deviations are far lower than the compositional variations with changing temperature predicted with Thermo-Calc. Thus, we conclude that for precipitates of more than $5 \mathrm{~nm}$ radius, the effect of compositional deviations due to curvature on the scattering contrast and consequently on $Q^{\prime}$ can be neglected.

In this study, the calculated average particle radius is always greater than $5 \mathrm{~nm}$, which is why we assume that this conjecture mostly holds. Our reasoning regarding the relation between $\gamma^{\prime}$ fraction and $Q^{\prime}$ is as follows: The scattering contrast changes with temperature, but precipitates of all sizes contribute evenly to the integrated intensity at all time. Measured and calculated integrated intensities agree in essence. Therefore, variations in $Q^{\prime}$ reflect developments in the entire $\gamma^{\prime}$ population.

\section{References}

C. Körner: Additive manufacturing of metallic components by selective electron beam melting - a review. International Materials Reviews 61 (2016) 361-377.

H. Helmer, A. Bauereiß, R.F. Singer, C. Körner: Grain structure evolution in Inconel 718 during selective electron beam melting. Materials Science and Engineering: A 668 (2016) 180-187.

L.N. Carter, M.M. Attallah, R.C. Reed: Laser powder bed fabrication of nickel-base superalloys: Influence of parameters; characterization, quantification and mitigation of cracking. Superalloys 2012 (2012) 577586.

V.D. Divya, R. Muñoz-Moreno, O.M.D.M. Messé, J.S. Barnard, S. Baker, T. Illston, H.J. Stone: Microstructure of selective laser melted CM247LC nickel-based superalloy and its evolution through heat treatment. Materials Characterization 114 (2016) 62-74.

H. Monajati, M. Jahazi, R. Bahrami, S. Yue: The influence of heat treatment conditions on $\gamma^{\prime}$ characteristics in Udimet 720. Materials Science and Engineering A 373 (2004) 286-293.

A.J. Goodfellow, E.I. Galindo-Nava, K.A. Christofidou, N.G. Jones, T. Martin, P.A.J. Bagot, C.D. Boyer, M.C. Hardy, H.J. Stone: Gamma prime precipitate evolution during aging of a model nickel-based superalloy. Metallurgical and Materials Transactions A 49 (2018) 718728.

A. Devaux, L. Nazé, R. Molins, A. Pineau, A. Organista, J.Y. Guédou, J.F. Uginet, P. Héritier: Gamma double prime precipitation kinetic in Alloy 718. Materials Science and Engineering A 486 (2008) 117-122. 

mechanisms of $\gamma^{\prime}$ reprecipitation in a Ni-based superalloy. Scientific Reports 6 (2016) 28650.

A.R.P. Singh, S. Nag, S. Chattopadhyay, Y. Ren, J. Tiley, G.B.

Viswanathan, H.L Fraser, R. Banerjee : Mechanisms related to different generations of $\gamma^{\prime}$ precipitation during continuous cooling of a nickel base superalloy. Acta Materialia 61 (2013) 280-293.

T. Grosdidier, A. Hazotte, A. Simon: Precipitation and dissolution processes in $\gamma / \gamma^{\prime}$ single crystal nickel-based superalloys. Materials Science and Engineering A 256 (1998) 183-196.

S.S. Babu, M.K. Miller, J.M. Vitek, S.A. David: Characterization of the microstructure evolution in a nickel base superalloy during continuous cooling conditions. Acta Materialia 49 (2001) 4149-4160.

X.P. Tan, D. Mangelinck, C. Perrin-Pellegrino, L. Rougier, Ch.-A. Gandin, A. Jacot, D. Ponsen, V. Jaquet: Spinodal decomposition mechanism of $\gamma^{\prime}$ precipitation in a single crystal Ni-based superalloy. Metallurgical and Materials Transactions A 45 (2014) 4725-4730.

D. Mukherji, R. Gilles, P. Strunz, S. Lieske, A. Wiedenmann, R.P. Wahi: Measurement of $\gamma^{\prime}$ precipitate morphology by small angle neutron scattering. Scripta Materialia 41 (1999) 31-38.

P. Strunz, D. Mukherji, R. Gilles, A. Wiedenmann, J. Rösler, H. Fuess: Determination of $\gamma^{\prime}$ solution temperature in Re-rich Ni-base superalloy by small-angle neutron scattering. Journal of Applied Crystallography 34 (2001) 541-548.

D.M. Collins, R.K. Heenan, H.J. Stone: Characterization of gamma prime $\left(\gamma^{\prime}\right)$ precipitates in a polycrystalline nickel-base superalloy using small-angle neutron scattering. Metallurgical and Materials Transactions A 42 (2010) 49-59.

P. Strunz, M. Petrenec, U. Gasser, J. Tobiáš, J. Polák, J. Šaroun: Precipitate microstructure evolution in exposed IN738LC superalloy. Journal of Alloys and Compounds 589 (2014) 462-471.

R. Gilles, D. Mukherji, H. Eckerlebe, L. Karge, P. Staron, P. Strunz, T. Lippmann: Investigations of early stage precipitation in a tungsten-rich nickel-base superalloy using SAXS and SANS. Journal of Alloys and Compounds 612 (2014) 90-97.

A. Deschamps, F. De Geuser: On the validity of simple precipitate size measurements by small-angle scattering in metallic systems. Journal of Applied Crystallography 44 (2011) 343-352.

M. Ramsperger, C. Körner: Selective electron beam melting of the single crystalline nickel-base superalloy CMSX-4®: From columnar 
grains to a single crystal. In: M. Hardy, E. Huron, U. Glatzel, B. Griffin, B. Lewis, C. Rae, V. Seetharaman, S. Tim: Superalloys 2016:

Proceeding of the 13th International Symposium of Superalloys (2016) 341-349.

N. Schell, A. King, F. Beckmann, T. Fischer, M. Müller, A. Schreyer: The high energy materials science beamline (HEMS) at PETRA III. Materials Science Forum 772 (2014) 57-61.

P. Staron, T. Fischer, T. Lippmann, A. Stark, S. Daneshpour, D. Schnubel, E. Uhlmann, R. Gerstenberger, B. Camin, W. Reimers, E. Eidenberger, H. Clemens, N. Huber, A. Schreyer: In situ experiments with synchrotron high-energy X-rays and neutrons. Advanced Engineering Materials 13 (2011) 658-663.

M. Ramsperger, R.F. Singer, C. Körner: Microstructure of the nickelbase superalloy CMSX-4 fabricated by selective electron beam melting. Metallurgical and Materials Transactions A 47 (2016) 1496-1480.

[23] D. Herzog, V. Seyda, E. Wycisk, C. Emmelmann: Additive manufacturing of metals. Acta Materialia 117 (2016) 371-392.

G. Beaucage: Approximations leading to a unified exponential/powerlaw approach to small-angle scattering. Journal of Applied Crystallography 28 (1995) 717-728.

R.B. Bergmann, A. Bill: On the origin of logarithmic-normal distributions: An analytical solution and its application to nucleation and growth processes. Journal of Crystal Growth 310 (2008) 31353138 .

J.O. Andersson, T. Helander, L. Höglund, P.F: Shi, B. Sundman: Thermo-Calc and DICTRA, Computational tools for materials science. Calphad 26 (2002) 273-312.

M. Fleck, F. Schleifer, M. Holzinger, U. Glatzel: Phase-field modeling of precipitation growth and ripening during industrial heat treatments in Ni-base superalloys. Metallurgical and Materials Transactions A 49 (2018) 4146-4157.

P. Strunz, R. Gilles, D. Mukherji, A. Wiedenmann, R.P. Wahi, J. Zrník: Microstructural characterization of single-crystal nickel-base superalloys by small-angle neutron scattering. Materials Structure 6 (1999) 91-95. $\gamma^{\prime}$ precipitates in a pre-deformed single-crystal Ni-base superalloy. Journal of Applied Crystallography (2011) 935-944. 
Time-resolved synchrotron diffractometry of phase transformations in high strength nickel-based superalloys. Acta Materialia 94 (2015) 244256.

Y.Q. Chen, E. Francis, J. Robson, M. Preuss, S.J. Haigh: Compositional variations for small-scale gamma prime $\left(\gamma^{\prime}\right)$ precipitates formed at different cooling rates in an advanced Ni-based superalloy. Acta Materialia 85 (2014) 199-206.

M.S.A. Karunaratne, P. Carter, R.C. Reed: On the diffusion of aluminium and titanium in the Ni-rich Ni-Al-Ti system between 900 and $1200^{\circ}$ C. Acta Materialia 49 (2001) 861-875.

M. Avrami : Granulation, phase change, and microstructure kinetics of phase change. III. Journal of Chemical Physics 9 (1941) 177-184.

J.Z. Zhu, Z.K. Liu, V. Vaithyanathan, L.Q. Chen: Linking phase-field model to CALPHAD: application to precipitate shape evolution in Nibase alloys. Scripta Materialia 46 (2002) 401-406.

F. Pyczak, B. Devrient, H. Mughrabi: The effects of different alloying elements on the thermal expansion coefficients, lattice constants and misfit of nickel-based superalloys investigated by X-ray diffraction. Superalloys 2004 (2004) 827-836.

G. Benecke, W. Wagermaier, C. Li, M. Schwartzkopf, G. Flucke, R. Hoerth, I. Zizak, M. Burghammer, E. Metwalli, P. Müller-Buschbaum, M. Trebbin, S. Förster, O. Paris, S.V. Roth, P. Fratzl: A customizable software for fast reduction and analysis of large X-ray scattering data sets: applications of the new DPDAK package to small-angle X-ray scattering and grazing-incidence small-angle X-ray scattering. Journal of Applied Crystallography 47 (2014) 1797-1803.

F. Zhang, J. Ilavsky, G.G. Long, J.P.G. Quintana, A.J. Allen, P.R. Jemian: Glassy carbon as an absolute intensity calibration standard for small-angle scattering. Metallurgical and Materials Transactions A 41 (2010) 1151-1158.

[38] P. Staron, W.V. Vaidya, M. Koçak: Precipitates in laser beam welded aluminium alloy AA6056 butt joints studied by small-angle neutron scattering. Materials Science and Engineering A 525 (2009) 192-199. F. De Geuser, A. Deschamps: Precipitate characterisation in metallic systems by small-angle X-ray or neutron scattering. Comptes Rendus Physique 13 (2012) 246-256.

[40] G. Beaucage, H.K. Kammler, S.E. Pratsinis: Particle size distributions from small-angle scattering using global scattering functions. Journal of Applied Crystallography 37 (2004) 523-535. 
J-C Zhao, M.F. Henry: CALPHAD - Is it ready for superalloy design? Advanced Engineering Materials 4 (2002) 501-508.

[42] M. Perez: Gibbs-Thomson effects in phase transformations. Scripta Materialia 52 (2005) 709-712. 